\section{Corticostriatal circuit dysfunction in Huntington's disease: intersection of glutamate, dopamine and calcium}

\section{Benjamin Ray Miller' \& llya Bezprozvanny ${ }^{\dagger 1}$}

'Department of Physiology, University of Texas Southwestern Medical Center at Dallas, Dallas, TX 75390, USA †Author for correspondence: Tel.: +1 2146456017 = Fax: +1 2146456018

n.ilya.bezprozvanny@utsouthwestern.edu

Huntington's disease (HD) is a noncurable and progressive autosomal-dominant neurodegenerative disorder that results from a polyglutamine expansion in the amino-terminal region of the huntingtin protein. The generation of rodent HD models has revealed that cellular dysfunction, rather than cell death alone, occurs early in the disease progression, appearing even before overt symptom onset. Much evidence has now established that dysfunction of the corticostriatal circuit is key to HD symptomology. In this article, we summarize the most current findings that implicate glutamate, dopamine and calcium signaling in this system and discuss how they work in concert to disrupt corticostriatal function. In addition, we highlight therapeutic strategies related to altered corticostriatal signaling in HD.

Huntington's disease (HD) is an autosomaldominant neurodegenerative disorder characterized by a triad of symptoms, including pronounced motor abnormalities (e.g. chorea, dystonia and bradykinesia), cognitive impairment and psychiatric disturbances [1]. Symptoms typically appear at middle age and undergo inexorable progression that leads to death $15-20$ years after onset [2]. The molecular underpinning of $\mathrm{HD}$ is a polyglutamine (polyQ)-repeat expansion in the amino-terminus of the $350-\mathrm{kDa}$ cytosolic protein huntingtin (Htt) [3], which is widely expressed in the brain and in non-neuronal tissues [4-6]. Penetrance of HD symptoms occurs when the polyQ tract in Htt exceeds approximately $35 \mathrm{Q}$, and there is an inverse correlation with age of HD onset and length of the polyQ expansion [7]. Although Htt is essential for embryogenesis [8,9], the exact function of the protein has yet to be elucidated. The generation of genetic rodent models of $\mathrm{HD}$, many varying in the degree in which they recapitulate features of the human condition, has been invaluable for probing the mechanisms by which mutant $\mathrm{Htt}(\mathrm{mHtt})$ leads to the disease pathogenesis. For extensive and recent reviews comparing different $\mathrm{HD}$ animal models, see [10-15]. However, after almost two decades since the discovery of $\mathrm{mHtt}[3]$, the precise mechanism(s) by which it mediates the disease pathophysiology is still far from evident.

The neuropathological hallmark of HD is degeneration of the striatum (caudate nucleus and putamen), with GABA-ergic medium spiny neurons (MSNs) being primarily affected $[2,16]$. Most evidence to date posits that MSN degeneration results from a toxic 'gain and/or loss of function' of mHtt, including, but not limited to, altered gene transcription, enhanced protease activity, protein misfolding, disruption of axonal transport, changes in electrophysiological properties and induction of apoptotic mechanisms (extensively reviewed in $[17,18]$ ). However, most of these hypotheses do not explain the selective vulnerability of MSNs in HD, nor do they account for the near-ubiquitous expression of $\mathrm{mHtt}$ in other neuronal circuits that might influence MSN degeneration [19]. It is now becoming well regarded that the clinical signs of HD manifest long before prominent cell death. Indeed, mounting evidence points to a more complicated picture of HD pathogenesis, whereby multifaceted cascades of neuronal dysfunction, particularly in the corticostriatal circuit, occur early in disease progression and contribute to symptomology (for recent reviews, see $[14,15,20])$. In this article, we discuss the emerging hypothesis that dysfunction of the corticostriatal circuit is a major component of HD pathophysiology and we emphasize this in light of deranged glutamatergic, dopaminergic and calcium $\left(\mathrm{Ca}^{2+}\right)$ signaling mechanisms that produce an excitotoxic environment that disrupts neuronal communication and leads to cell death in this system. Furthermore, we suggest relevant therapeutic strategies that target these deranged mechanisms.

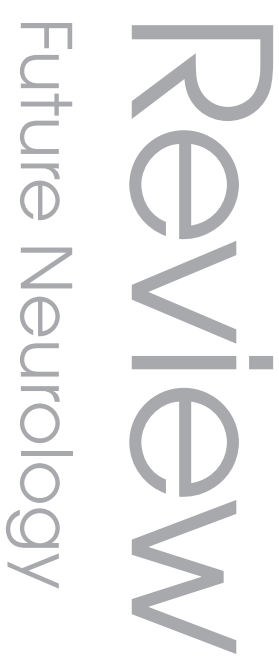

\section{Keywords \\ = apoptosis $\approx$ calcium = cortex \\ - dopamine \\ - electrophysiology \\ - glutamate = Huntexil ${ }^{\circledR}$ \\ - Huntington's disease \\ - medium spiny neuron \\ - neurodegeneration \\ - striatum - tetrabenazine}

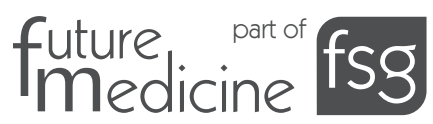


Overview of the corticostriatal circuit

The striatum is the main input hub of the basal ganglia (BG), serving to modulate afferent sensorimotor, cognitive and motivational information for the optimal control of behavior [21]. It receives widespread excitatory glutamatergic input from the entire cortex and specific thalamic nuclei, as well as dopaminergic innervation from midbrain dopamine neurons (substantia nigra pars compacta) [22]. These two primary striatal afferent projections converge onto striatal microcircuits and shape the activity of MSNs [23,24], which comprise approximately $98 \%$ of the striatal neuronal population $[23,25]$ and provide the sole output of the striatum to other BG nuclei [22]. Thus, MSNs are important integrators of information processing within BG circuits. For the purposes of this article, we focus on glutamatergic and dopaminergic innervation onto MSNs (FIGURe 1). Regulation of MSN activity within striatal microcircuits is driven by both interneurons and glia (astrocytes). Four classes of striatal interneurons have been identified, including fast-spiking GABA-ergic, cholinergic, nitric oxide synthase-positive and calretinin-positive neurons [26]. Striatal interneurons differentially express dopaminergic and cholinergic receptors and receive excitatory input from the cortex and thalamus. Although striatal interneurons make up only a small fraction of the total neuron population $(\sim 2 \%)$, they evoke profound regulation of MSNs by either inhibiting (GABA-ergic) or modulating (cholinergic) their activity $[23,25,26]$. However, a detailed understanding on how striatal interneurons shape MSN output in health and especially disease is strikingly lacking.

There are two populations of MSNs, termed the direct and indirect pathways, and they are classified on the basis of their respective projection targets and neurochemical composition (FIGURE 1) [27]. MSNs comprising the direct pathway preferentially express $D_{1}$-type dopamine receptors and the neuropeptides substance $P$ and dynorphin and project to the output nuclei of the BG (e.g., the internal segment of the globus pallidus and substantia nigra pars reticulate) [22,28]. Indirect pathway MSNs preferentially express $\mathrm{D}_{2}$-type dopamine receptors and enkephalin and project to the output nuclei of the BG through a network that includes the external segment of the globus pallidus in humans (entopeduncular nucleus in rodents) and subthalamic nucleus $[22,28]$. In the classical model of BG circuit function, which uses a simple rate code for neuronal processing, the direct and indirect pathways act in opposing ways to control motor behavior [29]. Activation of the direct pathway results in disinhibition of thalamocortical projections and facilitation of motor routines, while activation of the indirect pathway results in a net inhibition of thalamocortical projections and attenuation of movement-related processing. The direct and indirect pathways also differ in their cortical innervations, in that indirect pathway MSNs have stronger synaptic coupling with cortical inputs than do direct neurons [30]. Thus, activation and/or dysfunction of one or both of these dichotomous pathways can differentially influence BG processing. In this article, we will focus on pathophysiological changes in the corticostriatal circuit in the context of HD progression (Figure 1).

\section{Altered glutamatergic signaling in the Huntington's disease corticostriatal synapse Glutamate release}

Release of glutamate from cortical afferents into the striatum depends on the efficiency of transport, vesicular fusion to the plasma membrane and subsequent recovery of synaptic vesicles at axon terminals [31]. Dysfunction of this process is prominent in HD [32] and other neurodegenerative disorders [33]. A suggested role for $\mathrm{mHtt}$ in disrupting axonal transport first came from findings showing that $\mathrm{mHtt}$ microaggregates form in the axons of MSNs from (knock-in [KI]) mice that express full-length $\mathrm{mHtt}$ [34]. Axonal aggregation of $\mathrm{mHtt}$ occurred before the appearance of an overt HD phenotype, suggesting that it occurs early in HD pathology [34]. When studied in vitro from $\mathrm{mHtt-expressing}$ cells, aggregates were shown to block neuritic protein transport and cause neurite degeneration [34]. Other work has demonstrated deficient fast axonal vesicular transport in polyQ-repeat models of Drosophila [35], isolated squid axoplasm [36] and mouse primary cortical [37] and striatal neurons $[38,39]$. Moreover, using timelapse video microscopy, recent evidence revealed that $\mathrm{mHtt}$ causes increased stalling and accumulation of green fluorescent protein-tagged fast axonal transport vesicles in Drosophila larvae in vivo [40]. Disruption of axonal transport by $\mathrm{mHtt}$ also leads to decreased synaptic vesicle numbers and impaired neurotransmitter release in phenotypic HD mouse models [41]. Mechanistically, disruption of vesicular and organelle axonal transport appears to involve enhanced $\mathrm{mHtt}$ binding to Htt-associated protein (HAP1) [42]. HAP1, as well as Htt, interacts 
with membrane-bound organelles, transport vesicles, microtubules [43] and the $\mathrm{p} 150$ subunit of dynactin [44,45], which is necessary for proper function of the dynein motor protein.

Much of the machinery that mediates vesicular docking, fusion and recycling at the plasma membrane (see [31]), a process that is $\mathrm{Ca}^{2+}$-mediated, is also disrupted by $\mathrm{mHtt}$. Analysis of post-mortem cortical brain tissue from HD patients indicates reduced expression (compared with non-HD controls) of $\mathrm{N}$-ethylmaleimide-sensitive factor attachment protein receptor protein, synaptosomeassociated protein 25 , complexin II and rabphilin $3 a$, a Rab3a-interacting protein $[46,47]$. Similarly, post-mortem striatal tissue shows reduced expression of complexin II, $N$-ethylmaleimide-sensitive factor attachment protein receptor protein, synaptobrevin 2 and Rab3a [48]. Complexin II is reduced in R6/2 mice [48], and mRNA and protein levels of rabphilin $3 \mathrm{a}$ are depleted in the striatum and cortex of the R6/1 mouse model of HD [49]. Moreover, findings from post-mortem cortical tissue suggests that the recycling of neurotransmitter vesicles is perturbed by a loss of the endocytotic vesicle recovery regulators dynamin and PACSIN1, a phenomenon that appears in presymptomatic patients and progresses with disease severity $[47,50]$.

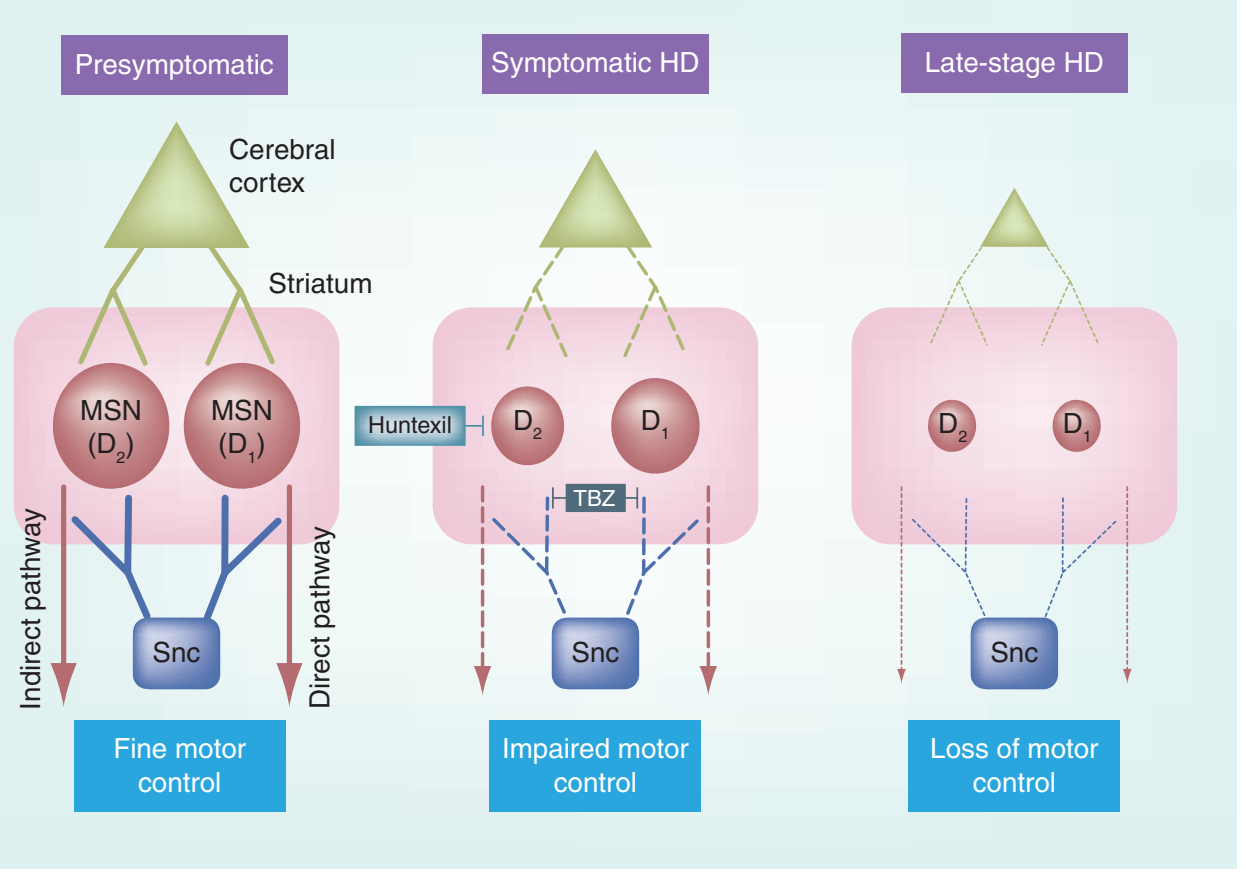

Figure 1. Circuit dysfunction in Huntington's disease. This model consists of direct $\left(D_{1}\right)$ and indirect $\left(D_{2}\right)$ MSNs and their primary glutamatergic and dopaminergic inputs. Presymptomatic HD (left) represents a time before overt HD symptoms appear. At this stage, the corticostriatal system appears to be intact and neuronal (e.g., MSN and cortical neuron) degeneration is not evident, yet subtle neuronal dysfunction begins to emerge. Symptomatic HD (center) represents a stage where neuronal dysfunction is characterized by marked dysregulation of glutamatergic and dopaminergic signaling, which leads to deranged intracellular $\mathrm{Ca}^{2+}$ and altered synaptic communication, including changes in the pattern of neuronal output. Much evidence now supports the notion that the corticostriatal circuit begins to disconnect at this symptomatic HD stage. The ramifications of this effect are not fully understood, but disconnection of both glutamatergic and dopaminergic input from MSNs correlates with the disease progression and probably represents a neuroprotective mechanism to defend against global excitotoxicity. The symptomatic stage of HD is also thought to be characterized by the preferential vulnerability of MSNs belonging to the indirect pathway $\left(D_{2}\right.$-containig MSNs) to the toxic effects of mutant huntingtin. To date, TBZ is the only US FDA-approved drug that has efficacy at this HD stage. The efficacy of Huntexil ${ }^{\circledR}$ (NeuroSearch, Denmark) in HD clinical trials also appears promising. Because these drugs are capable of modulating the interplay between glutamate and dopamine, it is conceivable that they improve circuit function and reduce MSN dysfunction. Late in HD progression (right), the corticostriatal circuit becomes completely disconnected and dysfunctional and is marked by prominent cell loss. It is questionable whether treatments would be efficacious at this stage in HD. Therefore, it will be important to design compounds that not only ameliorate but also impede the progressive dysfunction in HD pathogenesis. Thus, future experiments should focus attention on stopping the dysfunction that occurs in presymptomatic and symptomatic HD. HD: Huntington's disease; MSN: Medium spiny neuron; TBZ: Tetrabenazine. 
Functional evidence for diminished corticostriatal glutamate release comes from electrophysiological evidence of reduced miniature excitatory postsynaptic current (EPSC) frequencies in MSNs from R6/2 mice (relative to wildtypes [WTs]) at a time (5-7 weeks) when an overt behavioral phenotype appears [51]. Isolated large-amplitude synaptic events were also more frequent in R6/2 mice at this age [51]. Moreover, these electrophysiological events were correlated with reduced expression of the synaptic marker protein synaptophysin and the postsynaptic density protein PSD95 [51]. Using FM1-43 optical dyes in conjunction with cortical stimulation in slices, it was found that yeast artificial chromosome (YAC) transgenic HD mice with 128Q (YAC128) exhibit enhanced glutamate release from corticostriatal terminals at 1 month compared with WTs [52]. Interestingly, corticostriatal release progressively and markedly declined in an age-dependent manner (7 and 12 months) [52]. The age-related changes in corticostriatal release were not due to alterations in synaptic vesicle endocytosis or fusion; rather, they were correlated with a reduction in functional corticostriatal afferents [52].

As for receptor-mediated regulation of glutamate release, known involvement includes dopamine receptors, metabotropic glutamate receptors (mGluRs; specifically mGluR2), GABA receptors and cannabinoid receptors, all of which are localized to corticostriatal synapses [53-56]. Indeed, $\mathrm{HD}$ mouse models demonstrate reduced striatal expression of dopamine, mGluR and cannabinoid receptors at a time corresponding to the onset of behavioral symptoms [57-60]. Taken together, these findings suggest that the corticostriatal circuit becomes increasingly disconnected throughout the progression of HD, a process which has been hypothesized to be neuroprotective (see [20] for details), but which ultimately results in circuit degeneration and loss of motor control (Figure 1).

\section{Glutamate uptake}

The clearance of glutamate from the synaptic cleft is regulated by high-affinity glutamate uptake transporters located either on presynaptic terminals (e.g., GLAST and EAAC1) or on astrocytic processes, which couple tightly with synaptic terminals (e.g., glutamate transporter [GLT] 1/EAAT2). Evidence from in situ hybridization studies of HD postmortem neurostriatal tissue has shown that mRNA of the astrocytic GLT1 decreases with disease severity [6]]. Moreover, decreased $\left[{ }^{3} \mathrm{H}\right]$ glutamate uptake in the prefrontal cortex of post-mortem HD patients is correlated to CAGrepeat length [62]. Concomitant with findings in humans, HD mouse and primary neuronal models show reduced levels of GLT1 mRNA and protein [63-65]. Expression of other GLTs (e.g., GLAST and EAAC1) remains unchanged in HD models [63,64], suggesting that deficient glutamate uptake in HD is primarily due to dysfunctional GLT1. This is consistent with enhanced glutamate-induced toxicity of WT cortical and striatal neurons when cultured with astrocytes that express $\mathrm{mHtt}$ relative to WT astrocytes [65].

Related to these findings is the finding that expression of an extended polyQ peptide in a subset of Drosophila glial cells resulted in nuclear inclusions, progressive decline in the fly GLT dEATT1 and shortened lifespan [66]. Functional experiments using in vivo microdialysis in both anesthetized and behaving R6/2 mice have revealed decreased glutamate uptake in the striatum and cortex at $6-12$ weeks of age $[63,67]$. Indirect evidence of altered glutamate uptake by $\mathrm{mHtt}$ comes from data showing reduced release of the antioxidant ascorbic acid (AA; vitamin C) into the striatal extracellular fluid of R6/2 and 140CAG KI mouse models relative to WTs [68-70]. Release of AA into the striatum is directly proportional to glutamate uptake [71], a process that probably mitigates glutamate-dependent oxidative mechanisms, especially in the face of heightened synaptic glutamate release. Similarly, in 140CAG KI mice, trafficking of the glutamate/cysteine transporter EAAC1, which is required for de novo synthesis of the antioxidant glutathione, is impaired by defective Rab11, resulting in reduced cysteine uptake and glutathione production [72].

Overall, it appears that mHtt causes a dearth of glutamate uptake in the striatum. Importantly, GLT1 is responsible for the bulk of glutamate removal from the extracellular space $[73,74]$ and mounting evidence supports the view that it actively participates in the regulation of synaptic transmission [75]. Interestingly, reduced uptake of glutamate in vivo appears at approximately the same time (6-8 weeks) of reduced glutamate release from corticostriatal terminals in $\mathrm{R} 6 / 2$ mice ( $6-8$ weeks) $[63,67]$. It is conceivable that diminished glutamate uptake compensates for reduced release. However, increasing the level of glutamate uptake with ceftriaxone, a potent stimulator of GLT1 expression, reverses deficient glutamate uptake and ameliorates the behavioral phenotype in R6/2 mice (7 weeks) (Figure 2) [67]. In 
line with a GLT and AA interaction, upregulation of GLT1 was also shown to restore diminished AA release into the striatum [76]. Thus, it appears that reduced glutamate uptake is detrimental in HD. This is consistent with the prominent 'excitotoxicity hypothesis' in HD, whereby excessive glutamatergic drive leads to cellular toxicity (e.g., altered $\mathrm{Ca}^{2+}$ homeostasis and production of reactive oxygen species) and death (see [77-80]).

\section{Medium spiny neuron}

\section{$\mathrm{N}$-methyl-D-aspartate receptors}

$\mathrm{N}$-methyl-D-aspartate receptors (NMDARs) are ionotropic glutamate receptors that are highly permeable to $\mathrm{Ca}^{2+}$. Overload of glutamate in the synapse, enhanced receptor sensitivity or changes in receptor expression can lead to excessive NMDA activation and triggering of excitotoxic mechanisms, which are primarily

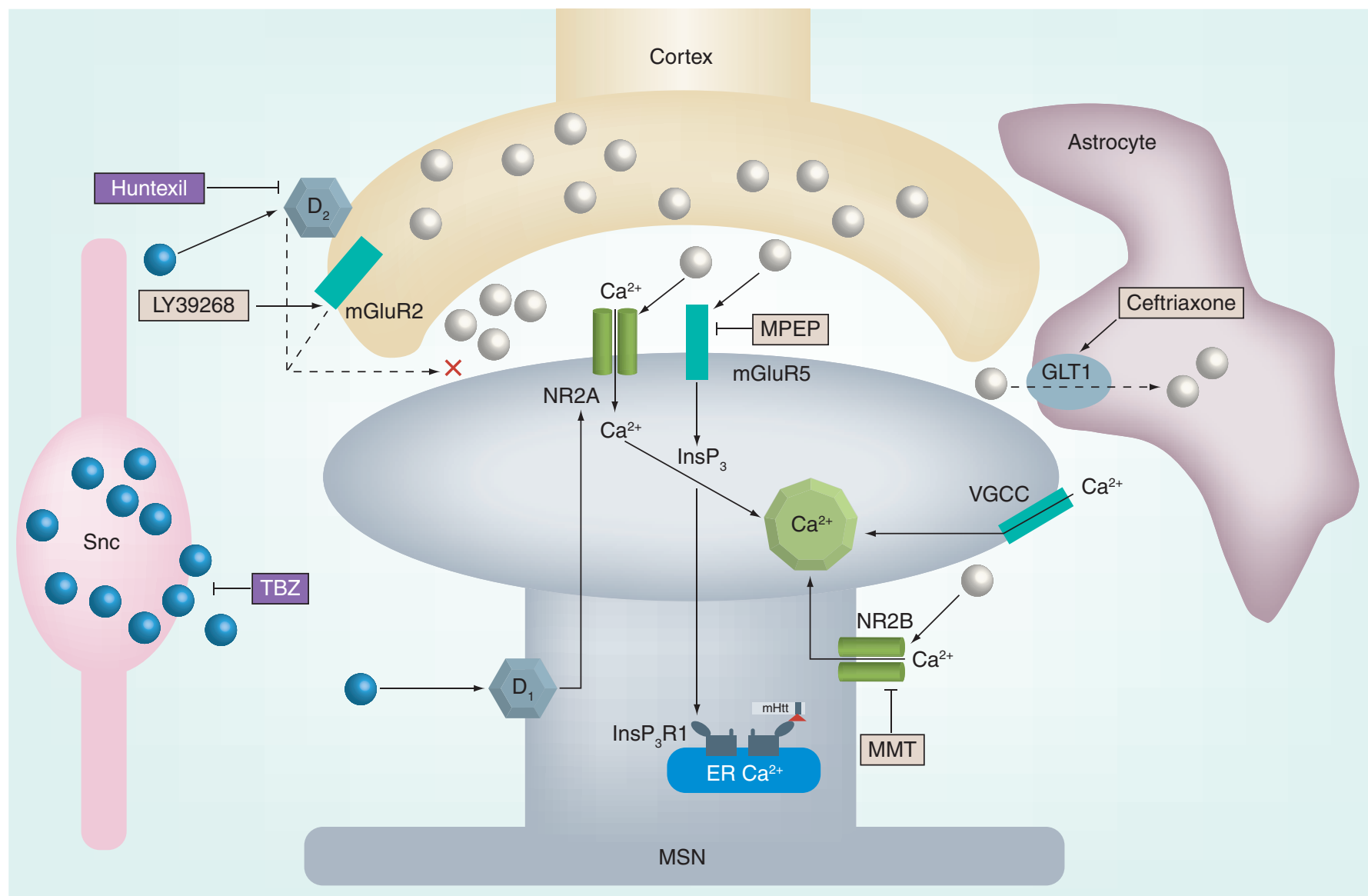

Figure 2. Synaptic dysfunction in Huntington's disease. In Huntington's disease (HD), mHtt expression results in altered corticostriatal synaptic function by synergizing glutamatergic and dopaminergic signaling, which increases intracellular $\mathrm{Ca}^{2+} \mathrm{mobilization}$ and leads to excitotoxicity. This model bypasses the cascade of molecular signaling pathways and illustrates the 'end result' of mHttmediated dysfunction of each pathway. Solid lines represent augmented function and dashed lines illustrate reduced function, respectively. Dopamine release from the substantia nigra pars compacta stimulates $D_{1}$ receptors on direct pathway MSNs and augments $\mathrm{N}$-methyl-D-aspartate (NMDA)-mediated (NR2A) glutamate activity. TBZ inhibits dopamine release and probably attenuates this response. Activation of $D_{2}$ receptor-mediated inhibition of glutamate release from presynaptic terminals is reduced in HD. Similarly, mGluR2 feedback-inhibition of glutamate release is also altered. Recent evidence has revealed that synaptic NR2A NMDA receptor signaling is not disrupted in $\mathrm{HD}$ and is in fact prosurvival, although the role of altered $\mathrm{D}_{1}$ activity on NR2A activity has not been fully elucidated. Therefore, it is conceivable that $\mathrm{D}_{1}$ activity results in pathological changes to NR2A function. Binding of mHtt sensitizes InsP $R 1$ to InsP ${ }_{3}$, resulting in supernormal $\mathrm{Ca}^{2+}$ release from the ER upon mGluR5 activation. Elevated intracellular $\mathrm{Ca}^{2+}$ is also caused by altered VGCC function. Moreover, $\mathrm{mHtt}$ expression potentiates NR2B NMDA receptor-mediated responses and further increases $\mathrm{Ca}^{2+}$ levels. Dysfunction and reduced expression of GLT1 impedes glutamate uptake from the synaptic cleft. Huntexil ${ }^{\circledR}$ (NeruoSearch A/S, Denmark), a dopamine stabilizer and $D_{2}$ modulator, demonstrated efficacy in human HD clinical trials. The mGluR2 agonist LY39268 and mGluR5 antagonist MPEP have shown promise in mouse models of HD. Low-dose MMT, which preferentially blocks NR2B activity, and ceftriaxone, which increases expression of GLT1, have also been successful in preclinical trials with HD mouse models. Taken together, $\mathrm{mHtt}$ results in a potentiated bombardment of glutamate-mediated excitotoxic cascades in MSNs.

ER: Endoplasmic reticulum; GLT: Glutamate transporter; InsP $P_{3}$ Inositol $(1,4,5)$-triphosphate; InsP $\mathrm{R}_{3}$ : Inositol $(1,4,5)$-triphosphate receptor; mGluR: Metabotropic glutamate receptor; $\mathrm{mHtt}$ : Mutant huntingtin; MMT: Memantine; MPEP: 2-methyl-6-(phenylethynyl)pyridine; MSN: Medium spiny neuron; TBZ: Tetrabenazine; VGCC: Voltage-gated $\mathrm{Ca}^{2+}$. 
driven by dysregulated intracellular $\mathrm{Ca}^{2+}$ homeostasis $[77,79,80]$. In fact, some of the earliest and most prominent animal models of HD were produced by intrastriatal injection of the NMDA agonist quinolinic acid. These models showed HD-like striatal lesions and recapitulated many of the behavioral features of the disease $[81,82]$. Importantly, these models set the stage for the NMDA-mediated 'excitotoxicity hypothesis' in HD [77,78]. Most of the recent attention to aberrant NMDAR activity in HD is focused on the NR1/NR2B over the NR1/NR2A subtype of NMDAR [78,83]. Notably, NR1/NR2B-type NMDARs are highly expressed in the striatum [84,85]. Because the overall role of NMDA function in HD has been described in great detail elsewhere $[20,78,83,86]$, this article will focus primarily on the compelling evidence that suggests NR2B-containing NMDARs, particularly those expressed extrasynaptically, contribute to MSN pathophysiology in HD [87].

An interaction between NR1/NR2B-type NMDARs and the polyQ expansion in Htt was first demonstrated by Raymond and colleagues using heterologous HEK293 cells coexpressing NMDAR subunits with either Htt-15Q or Htt-138Q [88]. They found that co-expression with NR1/NR2B-type and not NR1/NR2Atype NMDARs resulted in potentiation of NMDA-mediated currents in Htt-138Q and not Htt-15Q cells. Moreover, elevated NMDARinduced apoptosis of cells in the same HEK239 line showed specificity to NR1/NR2B over NR1/NR2A cells [89]. These findings were corroborated in the YAC mouse, whereby facilitation of NMDA-evoked current amplitude in MSNs from YAC72 and YAC128 mice compared with WTs was induced by the NR1/NR2B receptor [90,91]. Similarly, cultured MSNs from YAC72 mice showed enhanced NMDA-mediated cell death relative to WTs. Furthermore, treatment with ifenprodil, an NR2B-type selective antagonist, blocked most NMDA-mediated cell death in both YAC72 and WT mice [90]. The neuroprotective effect of ifenprodil was later recapitulated in YAC128 MSN cultures [92]. Findings from dissociated MSNs from presymptomatic R6/2 mice have revealed that NR2A and not NR1 or NR2B mRNA levels are reduced, which is concomitant with larger NR2B-mediated NMDAR currents compared with WTs [93].

That studies indicated NR2A-type NMDARs are targeted primarily to the synapse and NR2Btype receptors are preferentially expressed at extrasynaptic sites (outside the synapse) is intriguing (Figure 2) [94-96]. In fact, dual roles for synaptic and extrasynaptic NMDARs have been proposed (for details, see [97,98]). Whereas synaptic NMDARs activate prosurvival pathways (e.g., CREB phosphorylation, BDNF transcription, extracellular signal-regulated kinase $[E R K]$ activation and antioxidant mechanisms), extrasynaptic NMDARs activate pathways that mediate cell death (e.g., loss of mitochondrial membrane potential, inhibition of ERK and BDNF and dendritic blebbing) [99-101]. A recent study by Milnerwood and colleagues has shown that mHtt results in increased extrasynaptic NMDAR expression and currents [102] (see also [103]). Examination of extrasynaptic activation, by mimicking glutamate spillover into the synaptic cleft with either strong evoked EPSCs or paired-pulse stimuli revealed increased EPSC charge and elevated NMDA peak current and charge in presymptomatic (1 month) YAC128 MSNs relative to YAC18 mice [102]. Accordingly, application of TBOA, a GLT1 transport inhibitor that enhances glutamate spillover to extrasynaptic receptors, resulted in slowing of NMDAR EPSC kinetics in WT and YAC18 mice, but the slowing was consistently more augmented in YAC72 and YAC128 mice. Moreover, in the presence of TBOA, NMDA currents and peak charges were larger in YAC128 compared with WT and YAC18 mice, while YAC72 mice exhibited intermediate values. Altered TBOA-induced NMDA currents in YAC128 mice were ameliorated on application of ifenprodil, which blocks NR2B extrasynaptic signaling. Spontaneous NMDA activity was not altered by $\mathrm{mHtt}$, further suggesting involvement of NR2B-type and not NR2A-type NMDARs in altered MSN function. Surprisingly, treatment with low-dose memantine, which is thought to preferentially antagonize extrasynaptic over synaptic NMDARs, in 2-4-monthold YAC128 mice resulted in increased CREB activation and improved motor learning (number of falls when learning the rotarod) relative to WTs (Figure 2) [102]. Direct in vivo evidence for NR2B-mediated excitotoxicity in HD comes from recent findings demonstrating exacerbated striatal neurodegeneration in double-mutant mice that express 150Q and overexpress NR2B subunits [104].

It has been suggested that formation of $\mathrm{mHtt}$ macroinclusions is neuroprotective; conversely, formation of soluble $\mathrm{mHtt}$ microaggregates increases neurotoxicity. Indeed, the shortstop HD model, which expresses a short fragment (exons 1 and 2) of human Htt with 120 CAGrepeat expansions, does not manifest a HD 
behavioral phenotype and shows no loss in brain weight, striatal volume and striatal neuronal count at 12 and 18 months of age, despite the fact that it exhibits widespread $\mathrm{mHtt}$ nuclear inclusions [105]. Recent evidence from studies by Okamoto and colleagues demonstrated a relationship between synaptic versus extrasynaptic NMDA activity and $\mathrm{mHtt}$ inclusion formation. Consistent with NR2B-mediating toxicity pathways in $\mathrm{HD}$, low-dose memantine $(10 \mu \mathrm{M}$; to block extrasynaptic NMDAR activity) in primary rat striatal and cortical cultures transfected with WT or expanded Htt constructs, as well as from the YAC128 striatum, was found to increase $\mathrm{mHtt}$-containing macroinclusions [106]. On the other hand, high-dose memantine ( $30 \mu \mathrm{M}$; to block synaptic NMDARs) reduced the formation of $\mathrm{mHtt}$ inclusions. This effect was NMDA-specific as mHtt inclusion formation was unchanged by $\alpha$-amino-3-hydroxy5-methyl-4-isoxazole-propionic acid (AMPA) antagonism with CNQX. Interestingly, low-dose memantine protected $\mathrm{mHtt}$-transfected neurons from a glutamate challenge. Moreover, treatment with low-dose memantine increased $\mathrm{mHtt}$ inclusions, attenuated striatal volume loss and enhanced motor function (rotarod) in YAC128 mice at 12 months; the opposite effect was found when mice were treated with high-dose memantine. The molecular mechanism that regulates synaptic induction of $\mathrm{mHtt}$ inclusion formation appears to involve the chaperonin T complex-1 ring complex, while formation of soluble toxic $\mathrm{mHtt}$ appears to involve impairment of the CREB-PGC-1 $\alpha$ pathway. Taken together, these recent findings suggest that activation of extrasynaptic NMDARs leads to mHtt-mediated MSN dysfunction, while physiological levels of synaptic NMDAR activity renders MSNs more resistant to $\mathrm{mHtt}$ toxicity $[102,106]$.

How does mHtt augment NR2B activity? Numerous studies have investigated mRNA and protein expression of NMDARs in human post-mortem brains and in HD mouse models, yet no conclusive correlation exists between CAG-repeat number and receptor expression levels, nor receptor sensitivity (for discussion, see [83]). Some studies suggested that mHtt expression affects NMDAR function via a PSD95-dependent mechanism [107,108]. Indeed, treatment of YAC72 and YAC128 MSN cultures with the Tat-NR2B9C peptide $(200 \mathrm{nM})$, which blocks binding of NR2B with PSD95 and reduces surface expression of NMDARs, resulted in a marked reduction in NMDA-induced apoptosis [109]. Knockdown of PSD95 with siRNA resulted in the same effect in YAC128 MSNs [109]. Another possibility is altered NMDAR trafficking to the plasma membrane in the presence of $\mathrm{mHtt}$ [110]. Future experiments will be needed to clarify the exact molecular mechanisms responsible for increased NMDAR activity in HD MSNs.

From the above discussion, it is clear that hyperfunction of extrasynaptic NMDARs (NR2B) is a major problem in HD and these receptors warrant targeting. It would be interesting to test whether increasing the level of glutamate uptake with a compound such as ceftriaxone [67] in HD mice is sufficient to reduce glutamate spillover and subsequently attenuate extrasynaptic activity. However, one is still faced with the possibility of altered NR2B localization in the plasma membrane and/or changes in subunit composition (see [78]). Therefore, NR2B inhibitors (e.g., ifenprodil and memantine) are likely candidate targets. Indeed, low-dose memantine is neuroprotective in vitro $[106,111]$ and in vivo [102,106]. Memantine demonstrated some beneficial effects in a small scale pilot evaluation in HD patients [112], and a large Phase IV clinical trial of memantine in HD patients (NCT00652457) is currently recruiting participants. Furthermore, a continued search for compounds that positively regulate physiological levels of synaptic NMDAR (NR2A) activity and/or negatively regulate extrasynaptic NMDARs (NR2B) is warranted.

\section{Medium spiny neuron metabotropic glutamate receptors}

Metabotropic (G-protein-coupled) glutamate receptors are divided into three broadly defined groups (for reviews, see $[113,114])$. Group I (mGluR1,5) activation leads to generation of inositol $(1,4,5)$-triphosphate $\left(\mathrm{InsP}_{3}\right)$, which binds to the Ins $\mathrm{P}_{3}$ receptor $\left(\mathrm{Ins}_{3} \mathrm{R}\right)$ and mobilizes intracellular $\mathrm{Ca}^{2+}$ (see 'Deranged striatal calcium signaling in Huntington's disease medium spiny neurons' section for details). In the striatum, group I receptors are located on the postsynaptic cells (i.e., MSNs). Activation of group II (mGluR2,3) and group III (mGluR4,6,7,8) impedes formation of cAMP by inhibiting adenylyl cyclase. Group II (mGluR2) receptors are primarily located presynaptically in the striatum and regulate glutamate release via negative feedback control [15]. Analysis of mGluRs in the striatum of symptomatic R6/2 mice (12 weeks) using receptor-binding autoradiography, immunoblotting and in situ hybridization revealed decreases in mGluR1, mGluR2 and mGluR3 subtypes, but 
not mGluR5 [58]. However, increased binding to group I and II mGluRs without a concomitant increase in mRNA expression was found in YAC128 mice [116].

It appears that mGluR $1 / 5$ receptors, which activate signaling pathways that facilitate either prosurvival or prodeath cellular mechanisms [117], play a prominent role in $\mathrm{mHtt}$-mediated MSN pathology. That histological analyses suggests mGluR5 is more enriched in MSNs compared with mGluR1 [118-121] and that mGluR5-1mice exhibit only approximately $30 \%$ of WT 3,5-dihyroxyphenylglycine (DHPG; a specific mGluR5 agonist)-mediated $\mathrm{Ins}_{3}$ production, implicates mGluR5 activity as the primary driver of mGluR1/5 (hereafter mGluR5) signaling in MSNs. In our attempts to determine a molecular link between $\mathrm{mHtt}$ and altered $\mathrm{InsP}_{3} \mathrm{R} 1-$ mediated $\mathrm{Ca}^{2+}$ signaling in MSNs (see 'Deranged striatal calcium signaling in Huntington's disease medium spiny neurons' section for details), we probed the activation of the mGluR5 receptor with $10 \mu \mathrm{M} \mathrm{DHPG} \mathrm{[122].} \mathrm{Application} \mathrm{of} \mathrm{DHPG}$ to MSNs transfected with a Htt-82Q plasmid resulted in a marked increase in intracellular $\mathrm{Ca}^{2+}$ release (340:380 Fura-2 ratio) compared with those transfected with an EGFP plasmid alone (control) or a Htt-23Q plasmid [122]. Moreover, the effect is correlated with the polyQ expansion as MSNs transfected with an expanded Htt-138Q exhibited a more drastic $\mathrm{Ca}^{2+}$ response compared with Htt-82Q [122]. These data have revealed that $\mathrm{mHtt}$ increases the sensitivity of $\operatorname{Ins}_{3} \mathrm{R} 1$ activation by $\mathrm{Ins}_{3}$, resulting in deranged intracellular $\mathrm{Ca}^{2+}[122]$.

On the other hand, a prosurvival function for mGluR 5 comes from recent evidence by Ribeiro and coworkers [123]. For example, DHPG activation of mGluR5-mediated Ins $\mathrm{P}_{3}$ formation is desensitized in striatal slices from presymptomatic but not symptomatic $H d h^{Q 11 / / 2111}$ compared with $H d h^{220 / Q 20}$ mice [123]. Moreover, desensitization of $\mathrm{InsP}_{3}$ formation was protein kinase $\mathrm{C}$-mediated and inhibition of PKC increased Ins $\mathrm{P}_{3}$ formation in $H d h^{Q 111 / Q 111}$ to $H d h^{Q 20 / Q 20}$ levels. Furthermore, treatment of striatal neuronal cultures with DHPG and a PKC inhibitor, but not DHPG alone, increased cell death in $H d h^{Q 111 / Q 111}$ compared with $H d h^{220 / Q 20}$ mice. Another mGluR5 prosurvival pathway involves phosphorylation (activation) of ERK1/2 and AKT [124-126]. Application of $10 \mu \mathrm{M}$ DHPG in primary neuronal cultures and slices enhanced activation of ERK1/2 and AKT in $H d b^{\text {Q11//111 }}$ compared with $H d b^{\text {Q20/Q20 }}$ mice. Thus, activation of mGluR5 signaling pathways may be neuroprotective early in HD progression. Interestingly, however, mGluR5-mediated $\mathrm{Ca}^{2+}$ release in striatal neuronal cultures was higher in $H d h^{Q 111 / Q 111}$ compared with $H d b^{Q^{20 / Q 20}}$ mice [123], corroborating the findings of Tang et al., [122] and suggesting that the level of mGluR5 compensation in HD is not sufficient to mitigate deranged intracellular $\mathrm{Ca}^{2+}$. Therefore, it is doubtful that agonizing mGluR5 would be therapeutically beneficial.

Indeed, treatment with riluzole, a general antigluamatergic agent $[127,128]$ that is US FDAapproved for the treatment of amyotrophic lateral sclerosis [129], in R6/2 mice beginning at a presymptomatic stage delayed progressive weight loss and increased lifespan, but did not improve HD behavioral signs [130]. Similarly, riluzole partially protected cultured YAC128 MSNs from glutamate-induced apoptosis [111]. Although low-dose riluzole (50 mg twice daily) showed no efficacy in clinical trials [131], high-dose $(200 \mathrm{mg}$ per day) demonstrated beneficial symptomatic effects in HD patients [132]. In a more detailed preclinical study, R6/2 mice were treated with either LY379268 (mGluR2 agonist) or 2-methyl6-(phenylethynyl)-pyridine (MPEP; mGluR5 antagonist) [133]. Both LY379268 and MPEP treatment increased survival times and reduced early pathological hyperactivity in $\mathrm{R} 6 / 2$ mice relative to placebo-treated mice (Figure 2) [133]. Moreover, the decline in rotartod motor performance was attenuated in MPEP-treated, but not in LY379268treated R6/2 mice [133]. Interestingly, no change in intranuclear inclusion formation was found in either treatment, suggesting that mGluR2 and mGluR5 are not related to alterations in $\mathrm{mHtt}$ aggregation. Therefore, agonists of mGluR2, which putatively reduce corticostriatal glutamate release, and antagonists of mGluR5, which inhibit Ins $\mathrm{P}_{3}$ production, may be promising therapeutic targets in HD.

\section{Medium spiny neuron AMPA receptors}

AMPA-receptor activity mediates fast-acting postsynaptic glutamatergic responses and is partly responsible for relieving the $\mathrm{Mg}^{2+}$ block from NMDARs. Autoradiographic studies suggest that AMPA binding, but not mRNA expression, is elevated in YAC128 mice compared with controls [116]. It was recently found that evoked AMPA mean peak currents and current densities were increased at 1 month and did not differ at 7 months in acutely dissociated MSNs from YAC128 mice relative to WTs [52]. The age-related biphasic changes in AMPA currents appear to be concomitant with the degree of corticostriatal neurotransmitter release and not 
with AMPA-receptor affinity [52]. Analysis of spontaneous AMPA receptor-mediated EPSCs from MSN slices revealed a nonsignificant trend for lower frequencies and longer interevent intervals and a significant difference in interevent variance and decay kinetics in YAC128 compared with YAC18 mice (1 month of age), suggesting that presynaptic release is subtly altered [134]. Evoked receptor activity using a high, but not low, level of stimulation revealed reduced AMPA peak amplitudes in YAC72 and YAC128 mice (1 month of age) relative to YAC18 mice [134].

A clear disease progression-dependent reduction in AMPA responses are found in the more aggressive R6/2 HD model [51]. For example, spontaneous AMPA EPSC frequencies are not different in presymptomatic R6/2 mice (3-4 weeks of age), but a steady decline in frequency appears at the onset of an overt behavioral phenotype (5-7 weeks), becoming more severely impaired late in the disease (11-15 weeks) [51]. These differences persist in the presence of bicuculline or tetrodotoxin (to block inhibitory synaptic activity and action potentials, respectively), suggesting that the reduced spontaneous AMPA frequencies were a result of reduced presynaptic glutamate release [51]. No difference in spontaneous AMPA EPSC current amplitudes or decay kinetics appeared [51]. Overall, these findings support the idea that the corticostriatal circuit becomes increasingly disconnected throughout HD progression (FIGURE 1).

\section{Cortical glutamate receptors}

Although much work has focused on altered glutamate receptors in MSNs, little effort has been made to elucidate the role these receptors might have in the synaptic activity in cortical pyramidal neurons. Studies from R6/2 mice have shown that pyramidal AMPA currents from acutely dissociated sensorimotor cortices are smaller at 21 days (presymptomatic stage) and at 40 days (a time of early symptom-onset) [135]. Moreover, NMDA peak currents were also smaller in R6/2 pyramidal cells at 21 days. Although there was no difference in NMDA currents in R6/2 mice and WTs at 40 days, $\mathrm{Mg}^{2+}$ sensitivity was greater in R6/2 mice, resulting in smaller NMDA currents when recorded in the presence of $\mathrm{Mg}^{2+}$. No differences in AMPA or NMDA currents occurred at 80 days [135]. These findings demonstrate that glutamatergic signaling is reduced at an early stage in HD pathology, possibly contributing to the early manifestation in cognitive and/or motor dysfunction in HD. Recent findings demonstrate overt alterations in excitatory and inhibitory inputs to sensorimotor pyramidal neurons in three HD mouse models (R6/2, YAC128 amd CAG140 KI) [136]. Pyramidal neurons from the HD models exhibited a global increase in spontaneous frequencies of EPSCs relative to their respective controls. Greater spontaneous EPSC frequency was also apparent in the presence of tetrodotoxin, suggesting a problem with presynaptic release that is independent of action potentials. Similarly, evoked EPSCs had greater amplitudes and reduced paired-pulse ratios, indicating an increased probability of presynaptic release. Similarly to spontaneous EPSCs, inhibitory postsynaptic potentials were also increased in all HD models, but were reduced in R6/2 mice at a time corresponding to widespread phenotypic behavior [136]. Taken together, these findings suggest that mHtt induces altered pyramidal activity, which can have stark implications on MSN input. Remarkably, synaptic excitatory and inhibitory inputs onto cortical pyramidal neurons are differential and opposite to what has been found in MSNs, which has implications for therapeutic approaches [20].

\section{Aberrant dopaminergic signaling in the Huntington's disease corticostriatal synapse Dopamine receptors}

Many studies have shown altered dopaminereceptor expression both in human patients and rodent models. C-raclopride PET studies in the brains of living and symptomatic human HD patients indicate reduced dopamine receptor labeling is correlated with disease progression, cell loss and cognitive impairment [137]. Importantly, reduced dopamine-receptor binding is also prominent in the striatum and cortex of presymptomatic HD gene carriers, indicating dopamine dysfunction to be onboard before clinical manifestation of the disease [137]. Mirroring human HD, reduced dopamine $\mathrm{D}_{2}$-receptor binding is also evident in KI HD mice before HD phenotypic expression [138]. Similarly, numerous mouse models show reduced expression of dopamine receptors both before and after phenotypic expression [57,139,140]. Thus, reduced dopamine-receptor expression is a prominent feature of HD pathology. Interestingly, however, YAC128 mice do not express reduced dopamine-receptor binding [116].

\section{Dopamine release}

Microdialysis in R6/1 mice (16 weeks of age) in vivo showed a marked reduction $(70 \%)$ of basal extracellular dopamine levels compared 
with WTs [141]. Moreover, fast-scan cyclic voltammetric measurements have indicated impaired release of dopamine in $\mathrm{R} 6 / 2$ brain slices at 12 weeks of age $[142,143]$. Impaired release of dopamine is probably due to reduced quantal release as described with amperometry in adrenal chromaffin cells [143]. More recent findings suggest that the mechanism of impaired dopamine release in R6/2 mice (12 weeks of age) is a result of fewer dopamine reserve pool vesicles available for mobilization in the striatum [144]. This could be due in part to altered vesicular handling at synaptic terminals (see 'Glutamate release' section). Indirect evidence for dopamine dysfunction in HD comes from the fact that administration of amphetamine, methamphetamine and cocaine (compounds that potentiate physiological dopamine release [145]) to R6/2 mice results in a blunted stereotypical motor behavioral response compared with WTs, implying diminished dopamine release $[69,142,146]$. Our laboratory recently reached similar conclusions in studies of cocaine response in aging YAC128 HD mouse model [Wu ET AL., UNPUblished Data].

\section{Dopaminergic action in Huntington's disease}

As a neuromodulator, the action of dopamine in the striatum is complicated and little is known about how it is altered by mHtt. What is becoming clear is that $\mathrm{D}_{2}$ receptors reduce glutamate release and attenuate the activity of MSNs of the indirect pathway, while $\mathrm{D}_{1}$-receptor activation augments NMDA-mediated currents in MSNs of the direct pathway (Figure 2) (for review, see $[147])$. A role for dopamine in HD etiology was first described when over a third of asymptomatic relatives of HD patients developed dyskinesias in response to L-DOPA [148], which is consistent with dopamine-receptor hypersensitivity (see previous section). The concentration of dopamine in the striatum follows a dorsal to ventral gradient [149], as does the gradient of neuropathology in HD [150]. High concentrations of dopamine exert direct toxic effects on striatal neurons [151-156]. In addition, experimental evidence from our group and others suggests that in $\mathrm{HD}$, dopaminergic and glutamatergic signaling pathways act synergistically to enhance the sensitivity of striatal neurons to $\mathrm{mHtt}$ toxicity via disturbed calcium homeostasis [157] and dysregulated Cdk5 signaling [158]. All of these studies point to an important role of the dopaminergic pathway in HD and suggest that dopamine signaling constitutes a potential therapeutic target for HD treatment.
The importance of the dopamine pathway in vivo was evaluated in experiments with $\mathrm{HD}$ mice. Hyperdopaminergic transmission has been shown to accelerate the formation of $\mathrm{mHtt}$ aggregates and promote motor dysfunction in the $92 \mathrm{Q}$ KI HD mouse model [159]. In our experiments, YAC128 HD mice were fed with tetrabenazine (TBZ), a reserpine-like drug that depletes dopamine content in presynaptic vesicles by blocking the vesicular monoamine transporter type 2 (VMAT2) [160], or L-DOPA, which increases basal dopamine. Behavioral analysis (by rotarod, beamwalk or gait analysis) revealed improvement in YAC128 mice treated with TBZ and impaired performance when treated with L-DOPA [157,161]. Moreover, the behavioral deficits were consistent with brain pathology between the treatment groups; TBZ treatment ameliorated loss in brain weight, neuron loss and reduction in average cross-sectional areas [157,161]. Overall, these findings indicate that dopamine and glutamate signaling pathways act synergistically to induce deranged $\mathrm{Ca}^{2+}$ signaling, leading to $\mathrm{HD}$ symptomology and MSN degeneration $[157,161]$. Our studies were primarily focused on the role of $D_{1}$ receptors [157]. A parallel line of research indicated that $\mathrm{D}_{2}$ receptors may also play an important role in HD pathology by mediating the direct toxic effects of dopamine on MSN neurons [153]. On the other hand, $\mathrm{D}_{2}$ receptors have been largely implicated in neuroprotection [162]. Thus, it will be important for future studies to delineate the roles of $\mathrm{D}_{2}$ and $\mathrm{D}_{1}$ dopamine receptors in HD pathophysiology. It will also be important to understand the so-called HD-induced hyperdopaminergergic transmission in a system where receptor expression and dopamine release is reduced in the striatum.

Findings from functional imaging studies (FM1-43) have provided additional insight into dopamine and glutamate signaling in HD [52]. Evidence suggests that dopamine can filter corticostriatal glutamatergic signaling by action of $\mathrm{D}_{2}$ receptors, which leads to inhibition of exocytosis from corticostriatal terminals that possess the lowest probability of release [163]. Indeed, dopamine filtering is reduced in YAC128 slices at a late stage in disease progression (12 months) [52], paralleling reduced dopamine release from substantia nigra compacta afferents [144] and implicating disconnection of MSN afferents as a prominent feature of mid- to late-stage HD (Figure 1).

The first drug approved by the FDA in 2008 for HD treatment and the most efficacious to date was TBZ. TBZ is a potent inhibitor of 
VMAT2 and causes depletion of dopamine content in presynaptic vesicles [160]. Clinical trials indicate that TBZ significantly reduces chorea in symptomatic HD patients (Figure 2) $[164,165]$. The benefical effects of TBZ have also been observed in YAC128 mice; early treatment with TBZ attenuated motor coordination deficits and protected MSNs from degeneration in vivo $[157,161]$. By blocking VMAT2, TBZ depletes biogenic amines, including dopamine as well as serotonin and norepinephrine. Reduced levels of serotonin can cause depression. Indeed, it has been reported that many HD patients taking TBZ became severely depressed $[165,166]$. In the latest study, we also noticed that TBZ treatment groups of WT and YAC128 mice exhibited symptoms of depression, such as hypoactivity, immobility in a tail suspension test and impaired performance in forced-swim test paradigm [161]. Depression side effects are a major limitation for TBZ treatment for HD symptoms $[165,166]$.

A novel compound Huntexil ${ }^{\circledR}$ (pridopidine or ACR16; NeuroSearch A/S, Denmark) is a modulator of $\mathrm{D}_{2}$ receptor activity that has been recently developed by NeuroSearch for treatment of movement and psychiatric disorders. In a recently completed Phase III HD clinical trial (MermaiHD), Huntexil demonstarted significant clinical benefits (Figure 2). Huntexil treatment twice daily $(45 \mathrm{mg})$ for 6 months statistically improved both voluntary and involuntary motor symptoms in $437 \mathrm{HD}$ patients. Although the method of action of Huntexil is poorly understood, it is known to have antipsychotic effects and it appears to stimulate or inhibit dopamine depending on the basal dopaminergic tone (normalizing hypo- and hyper-dopaminergic behavior) [167], an effect only found in vivo, suggesting a complex mechanism of action that may be modulated by behavioral state [168]. Mechanistically, Huntexil appears to act as a state-dependent $\mathrm{D}_{2}$-receptor antagonist [168]. Although it is still unclear how TBZ and Huntexil act to attenuate the HD phenotype, we speculate that by modulating dopamine, they are capable of attenuating aberrant glutamatergic signaling at the corticostriatal synapse (FIGUREs 1 \& 2). Importantly, further analysis of results from a Phase III trial suggested that Huntexil exerted not only symptomatic benefits but was also able to slow the underlying disease progression. These clinical findings with Huntexil are consistent with the diseasemodifying effects of TBZ that we observed in the present and previous studies with the YAC128 HD mouse model [157,161]. It will be of interest to compare Huntexil with TBZ and with other clinically relevant $\mathrm{D}_{1}$ - and $\mathrm{D}_{2}$-receptor antagonists in HD mouse models. Obtained results will provide the opportunity to systematically compare the symptomatic and disease-modifying effects of these dopamine antagonists in HD, as well as evaluate potential side effects of these compounds. In summary, it will be important that future experiments delineate the dysfunction of dopamine signaling in $\mathrm{HD}$, especially since the drugs that modulate dopamine signaling (TBZ and Huntexil) are the only two drugs that so far have yielded significant benefit in patients.

\section{Deranged striatal calcium signaling in Huntington's disease medium spiny neurons \\ Mutant huntingtin sensitizes $\operatorname{Ins}_{3} \mathrm{R} 1$ \\ to $\operatorname{lnsP}_{3}$}

The Ins $\mathrm{P}_{3} \mathrm{R} 1$ is a $\mathrm{Ca}^{2+}$ release channel that plays a critical role in modulating intracellular levels of $\mathrm{Ca}^{2+}[169]$. Our laboratory has been heavily invested in elucidating the interaction between $\mathrm{mHtt}$ and $\mathrm{Ins}_{3}$, as well as other $\mathrm{Ca}^{2+}$-related mechanisms relevant to HD (for reviews, see $[80,86])$. We first discovered that $\mathrm{mHtt}$ binds directly and specifically to the C-terminal region of the type $1 \mathrm{InsP}_{3}$ receptor ( $\operatorname{Ins}_{3} \mathrm{R} 1$ ) [122]. Recently, unbiased high-throughput screening assays confirmed $\mathrm{mHtt}$ binding to $\mathrm{Ins}_{3} \mathrm{P}_{3} \mathrm{R} 1[170]$. Interestingly, the affinity of $\mathrm{mHtt}$ to $\mathrm{Ins}_{3} \mathrm{R} 1$ increases when $\mathrm{mHtt}$ is associated with HAP1a [122]. Moreover, mHtt, but not normal $\mathrm{Htt}$, augmented $\mathrm{Ins}_{3} \mathrm{R} 1$ activity in planar lipid bilayers [122]. Similarly, application of subthreshold concentrations of DHPG, an mGluR5 agonist, sensitized $\mathrm{Ca}^{2+}$ release in YAC128 primary MSN cultures [122]. This is consistent with the fact that glutamate-induced apoptosis of MSNs from YAC128 mice is mediated by mGluR5 and NR2B receptors [92]. In fact, specific blockade of $\mathrm{Ins}_{3} \mathrm{R} 1$ with 2-aminoethoxydiphenyl borate and enoxaparin is neuroprotective in the same [92]. In a follow-up study, we found disturbed $\mathrm{Ca}^{2+}$ signaling, enhanced glutamate-induced apoptosis and augmented NR2B activity in cultured MSNs from YAC128 mice, which express full-length human Htt, but these effects were completely absent in shortstop mice that express an aminoterminal fragment of mHtt (exons 1 and 2), suggesting a critical role for full-length $\mathrm{mHtt}$ in altered MSN Ca ${ }^{2+}$ signaling [91]. In more recent experiments, it was demonstrated that viral delivery of a peptide that disrupts mHtt association with InsP ${ }_{3} \mathrm{R} 1$ protected YAC128 mice MSNs in vitro and in vivo [171]. Augmented $\mathrm{Ins}_{3} \mathrm{P}_{3} \mathrm{R}$ activity further implicates mGluR5-receptor 
signaling in HD pathology. Importantly, inhibitors of InsP $\mathrm{P}_{3} \mathrm{R} 1$ may impede intracellular $\mathrm{Ca}^{2+}$ overload early in the disease and protect MSNs from glutamate-induce excitotoxicity.

\section{Mutant huntingtin alters voltage-gated $\mathrm{Ca}^{2+}$ channels}

High-voltage activated (HVA) $\mathrm{Ca}^{2+}$ channels (voltage-gated $\mathrm{Ca}^{2+}$ channels [VGCCs]) are important regulators of neuronal $\mathrm{Ca}^{2+}$ signaling and recent evidence highlights their function in HD. Five classes are expressed in MSNs: $\mathrm{N}$-type, P/Q-type, R-type, CaV1.2 L-type and CaV1.3 L-type [172]. It has been reported that Htt directly binds to the $\alpha 2 / \delta$ auxiliary subunit (CACNA2D1) of VGCCs [170]. Another study found that $\mathrm{N}$-terminal fragments of exon 1-containing $\mathrm{Htt}\left(\mathrm{Htt}^{\text {exon1 }}\right)$ bind the $\mathrm{CaV} 2.2$ pore-forming subunit of the $\mathrm{N}$-type $\mathrm{Ca}^{2+}$ channel [173]. Moreover, binding of $\mathrm{Htt}^{\text {exon1 }}$ to the $\mathrm{N}$-type $\mathrm{Ca}^{2+}$ channel displaces syntaxin $1 \mathrm{~A}$, resulting in enhanced $\mathrm{Ca}^{2+}$ influx [173]. Therefore, it is conceivable that increased binding of $\mathrm{Htt}^{\text {exon1 }}$ to $\mathrm{N}$-type channels would elevate $\mathrm{Ca}^{2+}$ influx by reducing syntaxin $1 \mathrm{~A}$ control over $\mathrm{N}$-type channels. Conversely, reduced concentration of $\mathrm{Htt}^{\text {exon1 }}$ would result in increased control of syntaxin 1A and reduce $\mathrm{Ca}^{2+}$ influx [173]. These data are somewhat in line with the fact that $\mathrm{mHtt}$ macroinclusions provide prosurvival effects by reducing $\mathrm{mHtt}$ binding to proteins [106]. Moreover, MSNs from R6/2 mice exhibited an initial increase in HVA Ca ${ }^{2+}$ density (3-6 weeks of age), which was followed by a reduction in HVA $\mathrm{Ca}^{2+}$ density (after 7 weeks of age) $[174,175]$. It is also relevant that genetic removal of the Drosophila L-type $\mathrm{Ca}^{2+}$ channel pore-forming subunit (Dmca1D) resulted in suppression of photoreceptor neurodegeneration in an HD fly model [176]. Related to these findings is that blockade of $\mathrm{L}$-type $\mathrm{Ca}^{2+}$ channels with isradapine resulted in significant neuroprotective effects in the chronic MPTP mouse model of Parkinson's disease [177]. Because specific blockers for VGCCs are now available, it will be important to further investigate VGCC activity in HD. Indeed, our laboratory is actively pursuing this concept and preliminary data suggest neuroprotective properties of the L-type $\mathrm{Ca}^{2+}$-channel inhibitor, nifedipine.

It is claimed that the old antihistamine Dimebon (latrepirdine) exerts neuroprotective effects by stabilizing neuronal $\mathrm{Ca}^{2+}$ signaling [178]. Based on this idea, Dimebon was proposed as a potential treatment for Alzheimer's disease $(\mathrm{AD})$ and HD and evaluated in clinical trials. Dimebon demonstrated significant positive effects in a 6-month randomized, doubleblinded, placebo-controlled Phase II trial of 183 patients with mild-to-moderate AD. At the conclusion of the trial, it was reported that after 12 weeks of taking Dimebon, patients significantly improved over baseline for AD Assessment Scale - cognitive subscale (ADAS$\operatorname{cog}$ ) score (mean drug-placebo difference: -4.0; $\mathrm{p}<0.0001)$ [179]. Dimebon was also recently evaluated in Phase II HD clinical trial conducted by the Medivation and Huntington Study Group (DIMOND). It was discovered that Dimebon had no significant effect on Unified HD Rating Scale measures of HD progression or on ADAS$\operatorname{cog}$ readout [180]. A small benefit was observed in Mini-Mental State Examination (MMSE) measurements of cognitive performance [180].

The mechanism of action of Dimebon remains unclear [181]. It has been initially suggested that Dimebon acts by inhibiting NMDARs [182], VGCCs [183] and the mitochondrial permeability transition pores [184]. Our laboratory evaluated Dimebon in experiments with primary neuronal cultures from a YAC128 HD mouse model and demonstrated that concentrations of at least $10 \mu \mathrm{M}$ were required to inhibit VGCCs and NMDARs [185]. At least $50 \mu \mathrm{M}$ of Dimebon was needed to exert neuroprotective effects in glutamate excitotoxicity models [185]. The concentrations of Dimebon needed to affect $\mathrm{Ca}^{2+}$ signaling and mitochondria in all published reports [182-185] were at least $10 \mu \mathrm{M}$, which is far above the physiological range. In order to search for more physiologically relevant targets of Dimebon, we performed an unbiased screen for Dimebon targets [185]. It was discovered that Dimebon potently inhibits $\alpha_{1 B}$-adrenergic receptors, histamine H1 receptors and serotonin 5-HT6 receptors, as well as a number of additional receptors [185]. These findings were recently confirmed in an independent study [186]. It is most likely that some cognitive effects of Dimebon observed in AD and HD clinical trials $[179,180]$ are due to interactions with these receptors. In particular, the ability of Dimebon to inhibit 5-HT6 serotonin receptors with high affinity $\left(\mathrm{K}_{\mathrm{i}}=34 \mathrm{nM}\right)$ [186] is of interest. Serotonin 5-HT6 receptors are known targets for cognitive enhancement that have been previously considered for AD treatment [187]. A recently published evaluation of Dimebon in the animal model confirmed the ability of Dimebon to interact with 5-HT6 receptors in vivo and to exert acute behavioral effects similar to the specific 5-HT6 receptor 
antagonist SB-399885 [188]. These studies support the hypothesis that the cognitive effects of Dimebon are most likely due to its ability to inhibit 5-HT6 serotonin receptors. In addition, other potential effects of Dimebon, such as its effects on amyloid metabolism [189] and protein aggregation [190,191], may have contributed to some of the results observed in the clinic.

The large, Phase III, 26-week clinical trial of Dimebon in AD patients sponsored by Medivation and Pfizer has been recently completed (CONNECTION trial) and the results were disappointing, as treatment with Dimebon did not significantly improve ADAS-cog $(\mathrm{p}=0.86)$ or any other primary or secondary efficacy end points [181]. The Phase III study of Dimebon in HD (HORIZON trial) sponsored by Medivation and Pfizer is currently recruiting. It is not clear at the moment if development of Dimebon for $\mathrm{AD}$ and $\mathrm{HD}$ will continue.

\section{Dysfunction of corticostriatal neuronal communication in Huntington's disease}

Evidence suggests that aberrant synaptic function is one of the earliest detectable effects of $\mathrm{mHtt}$ and may correlate with the clinical signs that appear during early symptom progression. For example, one of the earliest changes in MSNs is an increase in the membrane input resistance [192]. Other intrinsic membrane properties (e.g., cell capacitance, time constants and alterations in $\mathrm{K}^{+}$channels and $\mathrm{Ca}^{2+}$ conductances) have also been shown to be disrupted in MSNs and cortical pyramidal cells in HD models (for review, see [20]). However, one overlooked question is what happens to neuronal communication (i.e., spike output) when mHtt-mediated dysfunction goes awry in the corticostriatal circuit?

Attempts have aimed to answer this question. Current clamp recordings from MSNs in slices of R6/2 mice have shown that action potentials display shorter interspike intervals and exhibit greater spike adaptation, equating to an irregular pattern of firing relative to WTs [192]. More recent studies have taken advantage of multiwire bundle electrodes implanted in the brain of rodents in vivo, enabling simultaneous electrophysiological recordings from many neurons while animals are awake and behaving. Recordings from putative striatal MSNs in behaving HD mice revealed elevated firing frequencies in R6/2 mice (1-2 months old), but not in 140CAG KI mice (2-12 months old), relative to WTs [193,194]. However, a more detailed analysis of spike patterns indicated reduced indices of burst activity (e.g., burst rate, percentage of spikes in bursts and magnitude of burst) in both HD models, although burst rate was not different in 140CAG KIs compared with controls [194]. To better understand MSN population activity, cross-correlation histograms, which measure spike timing between neuron pairs, were constructed and revealed a marked reduction in correlated neuronal activity in both HD models [194]. Similar recordings in MSNs from a recently generated transgenic rat model of HD (tgHDrat; 10-15 months old) [195] revealed no changes in individual MSN firing patterns, but a marked reduction in correlated firing [196]. These changes are not specific to the striatum. Correlated firing is also greatly reduced in pyramidal neurons from the prefrontal cortex of R6/2 mice (2-3 months old) and 140CAG KI mice (2-8 months old) and in the motor (M1) cortex of R6/2 mice (1-3 months old; M1 recordings were not performed in 140CAG KI mcie) [197,198]. Moreover, pyramidal neurons from both cortical areas in R6/2 mice showed altered spike activity patterns in individual neurons, a phenomenon that was absent in 140CAG KI mice [166-167].

Taken together, these findings suggest $\mathrm{mHtt}$ alters neuronal output in diverse brain areas and this deficit appears early in disease progression and is persistent in all three HD models. Loss of correlated activity in the striatum and cortex was found in all HD models at all ages tested, suggesting a loss of coordinated circuit function. For example, MSNs require temporally convergent cortical excitation to bring them into a depolarized up-state to elicit firing [199]. Therefore, it is likely that loss of coordinated activity in the cortex is reflected by a loss of coordinated MSN activity. Interestingly, however, individual activity patterns were altered in MSNs and not in prefrontal pyramidal neurons from 140CAG KI mice [194,197], suggesting that MSN output may become disrupted earlier in disease progression. Because proper function of neuronal circuits is important to guide behavior, it is conceivable that these altered activity patterns contribute directly to HD symptomology. Indeed, treatment with AA (300 mg/kg) not only restores the level of AA released into striatum (see 'Glutamate uptake' section) and attenuates the HD behavioral phenotype [200], but significantly attenuates the elevated firing rates in R6/2 mice [193]. It will be intriguing to test whether future candidate therapeutics are capable of restoring the natural activity patterns of neuronal populations in behaving animals. 


\section{Conclusion}

It is now well established that mHtt causes neuronal dysfunction long before neuronal death in HD pathology. In fact, neuronal dysfunction in the corticostriatal circuit occurs even before appearance of an overt phenotype in HD mouse models. Thus, targeting mechanisms that lead to dysfunction early in disease progression will probably be promising in the clinic. We suggest that aberrant glutamatergic, dopaminergic and $\mathrm{Ca}^{2+}$ signaling mechanisms work in concert to cause dysfunction of MSNs. Indeed, these events occur early in HD pathogenesis and correlate well with symptom severity in animal models of HD $[20,80,83,86]$.

What is the major event(s) that leads to corticostriatal dysfunction? It appears that the 'excitotoxicity hypothesis' of HD has validity. Intracellular $\mathrm{Ca}^{2+}$ overload is particularly toxic. Whatever the mechanism(s), mHtt appears to enhance sensitivity of NR2B extrasynaptic- and mGluR5mediated currents, which alters intracellular $\mathrm{Ca}^{2+}$ buffering by either excess $\mathrm{Ca}^{2+}$ entry or by increasing production of $\mathrm{Ins}_{3}$, respectively. Moreover, altered $\mathrm{mHtt}$-induced dopamine signaling synergizes augmented glutamate responses, rendering further aberrant intracellular $\mathrm{Ca}^{2+}$. Binding of $\mathrm{mHtt}$ to $\mathrm{Ins}_{3} \mathrm{P}_{3} 1$ also potentiates intracellular $\mathrm{Ca}^{2+}$ release. In order to reduce excitotoxic burden and avoid cell death, striatal neurons 'disconnect' from glutamatergic cortical input. As a result of this, the 'disconnected' corticostriatal circuit can no longer operate correctly and HD symptomology ensues. At this early stage, dopamine antagonists and stabilizers (TBZ and Huntexil) are able to correct the corticostriatal circuit function and alleviate symptoms of the disease. Eventually, excitotoxic mechanisms overwhelm normal cellular processes, leading to cell death of striatal neurons and late-stage disease.

\section{Future perspective}

Although it has been almost two decades since the discovery of $\mathrm{mHtt}$, efficacious therapies for HD symptomology are lacking. Why have there been so few success and so many failures in the clinic? The answer probably stems from the fact that $\mathrm{mHtt}$ disrupts cellular processes in diverse and diffuse neuronal systems. Therefore, targeting any one molecular event in a particular cell, a 'one-hit-wonder drug' per se, may not show efficacy; rather, combinatorial therapies might be needed.

The clinical success of TBZ and Huntexil are steps in the right direction, but their mechanisms of action are complex and not well characterized.
Indeed, especially little is known about Huntexil's mechanism of action. Future experiments should be designed to identify the mechanisms by which TBZ and Huntexil act to ameliorate HD symptomology. This feat is not trivial since their actions rely on an intact and physiologically relevant corticostriatal system and its relevant afferents (i.e., dopamine input from substantia nigra pars compacta). The recent focus on the dual roles of NMDARs (i.e., extrasynaptic NR2Bs versus synaptic NR2As) is also of great interest. Although more work is needed to fully understand the dichotomy of NMDARs, it appears that global inhibition of glutamatergic signaling would impede prosurvival mechanisms mediated by physiological levels of presynaptic activation. This may explain the moderate effects of riluzole in preclinical trials $[130,185]$ and its only modest effect in clinical trials [131,132]. Preliminary clinical evidence suggests memantine improves motor symptoms and retards the progression of HD patients [112,201]. It is possible that NR2B-specific antagonists, such as infenprodil and low-dose memantine, might prove useful in the clinic. Memantine demonstrated some beneficial effects in a small-scale pilot evaluation in HD patients [112], and a large Phase IV clinical trial of memantine in HD patients is currently in progress (NCT00652457). In collaboration with Roche, Evotec (Germany) recently developed NR2B-specific antagonists (EVP101 and EVP103). Evaluation of these compounds in HD patients and in HD mouse models will be of great interest. Similarly to NMDARs, a dual role for mGluRs is intriguing. Compounds that agonize mGluR2 (e.g., LY379268) would reduce corticostriatal glutamate release, and those that antagonize mGluR5 (e.g., MPEP), which would inhibit $\mathrm{InsP}_{3}$ production, may also hold promise in the clinic. Although the HD field is much improved from almost two decades ago, it is clear that future studies will be needed to identify additional novel and more rational targets.

What other considerations should be made in the HD field in the future? Evidence suggests that MSNs belonging to the indirect pathway ( $\mathrm{D}_{2}$-containnig MSNs) are more vulnerable to $\mathrm{mHtt}$ than those belonging to the direct pathway $[202,203]$. This phenomenon could be due in part to the fact that indirect-pathway MSNs are hyperexcitable, owing to stronger synaptic coupling with cortical inputs [30] and enhanced spontaneous EPSCs relative to direct-pathway MSNs [204]. However, it has been difficult to delineate whether dysfunction occurs earlier in indirect versus direct MSNs. Using labeling methods [204] to identify direct and indirect 
MSNs, it is now possible to test how mHtt differentially affects these neurons. Moreover, because direct and indirect MSNs express different receptor types and differ in their neurochemical make-up (see 'Overview of the corticostriatal circuit' section), it will be necessary to take these

Executive summary

\section{Altered glutamatergic signaling in the Huntington's disease corticostriatal synapse}

- Expression of mutant huntingtin alters corticostriatal glutamate release (and possibly other neurotransmitter releases) by interrupting axonal transport, vesicular release, vesicular reuptake and presynaptic receptor regulation.

- Glutamate uptake is diminished in Huntington's disease (HD), which is primarily a result of dysregulated and decreased glutamate transporter 1 expression.

- Extrasynaptic NR2B N-methyl-D-aspartate receptor activity is selectively potentiated over presynaptic NR2A activity in medium spiny neurons (MSNs) from YAC128 mice.

- Activation of NR2B induces detrimental signaling pathways, while physiological activation of NR2A promotes neuronal survival in YAC128 mice.

- Activation of the metabotropic glutamate receptor 5 receptor augments inositol $(1,4,5)$-triphosphate $\left(\right.$ InsP $\left._{3}\right)$ production and increases intracellular $\mathrm{Ca}^{2+}$ mobilization in YAC128 mice.

- Dysregulated excitatory and inhibitory synaptic activity in cortical pyramidal neurons is opposite to changes in activity of MSNs.

- The noncompetitive $N$-methyl-D-aspartate receptor inhibitor memantine demonstrated neuroprotective effects in experiments with YAC128 MSN cultures and in animal studies with YAC128 mice.

- Memantine demonstrated some beneficial effects in a small-scale pilot evaluation in HD patients and a large Phase IV clinical trial of memantine in HD patients is currently in progress.

\section{Aberrant dopaminergic signaling in the HD corticostriatal synapse}

- The striatum receives massive dopamine input from substantia nigra and the modulating dopamine signaling pathway provides an attractive opportunity for therapeutic intervention.

- Dopamine and glutamate signaling pathways act synergistically to induce deranged intracellular $\mathrm{Ca}^{2+}$ signaling and neurotoxcity in MSNs from YAC128 mice.

- Downregluation of $D_{2}$ and $D_{1}$ receptors is one of the earliest events during progression of human HD pathology.

- Dopamine modulators and antagonists may have benefit for both symptomatic relief and as neuroprotective agents.

- Tetrabenazine (TBZ) is selective inhibitor of vesicular monoamine transporter type 2, which depletes dopamine and serotonin content in presynaptic vesicles.

- Long-term treatment with TBZ alleviated the motor phenotype and reduced neuronal loss in YAC128 mice.

- Human clinical trials indicated that TBZ significantly reduces chorea in symptomatic HD patients, and TBZ is currently the only drug approved by the US FDA for HD treatment.

- Due to antiserotonergic action, TBZ can cause severe depression in some HD patients, limiting its therapeutic applications

- Huntexil (pridopidine; ACR16) is a novel state-dependent antagonist of $D_{2}$ receptors developed by NeuroSearch A/S (Denmark).

- Huntexil demonstarted symptomatic and disease-modifying benefits in clinical trials with HD patients.

- It will be of great interest to perform preclinical evaluation of Huntexil in HD mouse models.

\section{Deranged striatal calcium signaling in HD medium spiny neurons}

- Full-length $\mathrm{mHtt}$ sensitizes InsP $_{3} \mathrm{R} 1$ to InsP $_{3^{\prime}}$ which leads to increased intracellular $\mathrm{Ca}^{2+}$ signaling and neurotoxicity. Blockade mHtt association with InsP $\mathrm{P}_{3} \mathrm{R} 1$ stabilizes $\mathrm{Ca}^{2+}$ signaling and is neuroprotective in vitro and in vivo in YAC128 mice.

- Voltage-gated calcium channel function is altered by $\mathrm{mHtt}$, leading to increased intracellular $\mathrm{Ca}^{2+}$ and neurotoxicity.

- $\mathrm{Ca}^{2+}$ signaling inhibitors hold therapeutic potential for the treatment of HD.

\section{Dysfunction of corticostriatal neuronal communication in HD}

- Altered activity patterns in single neurons and in neuronal populations is a common feature of cortex and striatum that is found in multiple behaving rodent HD models.

\section{Conclusion}

- Dysfunction of the corticostriatal circuit is prominent in HD pathophysiology.

- Aberrant glutamatergic, dopaminergic and $\mathrm{Ca}^{2+}$ signaling are key to corticostriatal dysfunction.

- Dysfunction of the corticostriatal circuit alters neuronal output in the cortex and striatum.

\section{Future perspective}

- Because TBZ and Huntexil are clinically promising therapies, it will be imperative to continue with preclinical studies to further investigate their mechanisms of action.

- It will be important to investigate the role of the direct and indirect MSN pathways in HD and to evaluate effects of dopamine antagonists on their activity in HD models.

- It will be important to investigate the role of striatal interneurons in HD.

- It will be important to characterize the extent that MSN dysfunction is determined by dysfunction of cortical (and other circuitry) input. 
into consideration when designing therapeutics. It is also relevant that striatal interneuron death appears to be spared by the deleterious effects of $\mathrm{mHtt}$, although it is conceivable that these neurons could be dysfunctional. However, very few studies have attempted to determine this. In one such study, it was found that cholinergic interneurons from R6/2 mice exhibit reduced synaptic plasticity (long-term potentiation) [205].

Although $\mathrm{mHtt}$ aggregation is a cell-autonomous process, recent evidence has revealed that $\mathrm{mHtt}$ expression in multiple neuron types and in glia is necessary to fully induce HD neuropathology and symptomology (i.e., noncellautonomous toxicity and pathological cell-cell interactions) [206-208]. For example, progressive motor deficits and cortical neuronal pathology are absent when $\mathrm{mHtt}$ is expressed selectively in pyramidal neurons in HD mice, but not when $\mathrm{mHtt}$ is expressed in all neurons, including interneurons [208]. Recordings from cortical pyramidal neurons revealed a reduction in GABA-ergic transmission that was absent when mHtt was restricted to pyramidal neurons [208], suggesting a prominent role of interneurons in HD pathology. The presence of $\mathrm{mHtt}$ in astrocytes and dopaminergic neurons also markedly alters corticostriatal function.

Does the striatum or the cortex first become dysfunctional in HD pathogenesis? Although no conclusive evidence has surfaced, the early appearance of cognitive deficits before the onset of motor symptoms in HD patients and in several rodent models of HD suggests that the cortex might become dysfunctional first. If so, would impeding HD progression in the cortex abate progression in the striatum? Perhaps the opposite is true and dysfunction of the striatum alters basal ganglia processing, which, in turn, would begin to affect the cortex. Partial evidence for striatal dysfunction independent of the cortex comes from findings that show motor impairment and changes in striatal gene expression when $\mathrm{mHtt}$ is expressed in the forebrain but is specifically excluded in the neocortex [209]. It is also important to consider that synaptic dysfunction of the striatum does not mirror dysfunction in the cortex [136]. Moreover, many of the changes in synaptic communication in the corticostriatal circuit are biphasic, changing from one direction to another as the disease progresses [20]. Thus, it is clear that mHtt-mediated dysfunction of the corticostriatal system is a circuit problem, and this idea should be incorporated into rational therapeutic designs for HD. Furthermore, elucidating HD-induced dysfunction of midbrain dopamine neurons and especially the thalamostriatal pathway, which has largely been ignored in preclinical investigations, will also be of great importance for drug design.

\section{Acknowledgements \\ We thank Leah Benson for administrative assistance and members of our laboratory and our colleagues for stimulating discussions. \\ Financial \& competing interests disclosure \\ Ilya Bezprozvanny is a holder of the Carla Cocke Francis Professorship in Alzheimer's Research. This work on Huntington's disease is supported by the CHDI foundation and the NIH grant NINDS ROI NS056224. The authors have no other relevant affili- ations or financial involvement with any organization or entity with a financial interest in or financial conflict with the subject matter or materials discussed in the manuscript apart from those disclosed. \\ No writing assistance was utilized in the production of this manuscript.}

\section{Bibliography}

Papers of special note have been highlighted as:

- of interest

-. of considerable interest

1. Harper PS: Huntington's Disease. Harper PS (Ed.). WB Saudners Co. Ltd, UK (1991).

2. Vonsattel JP, DiFiglia M: Huntington disease. J. Neuropathol. Exp. Neurol. 57, 369-386 (1998).

3. Novel gene containing a trinucleotide repeat that is expanded and unstable on Huntington's disease chromosomes. The Huntington's disease collaborative research group. Cell $72(6)$, 971-983 (1993).

4. Li SH, Schilling G, Young WS III et al.: Huntington's disease gene (it15) is widely expressed in human and rat tissues. Neuron 11(5), 985-993 (1993).
5. Strong TV, Tagle DA, Valdes JM et al.: Widespread expression of the human and rat Huntington's disease gene in brain and nonneural tissues. Nat. Genet. 5(3), 259-265 (1993).

6. Sharp AH, Loev SJ, Schilling G et al.: Widespread expression of Huntington's disease gene (it15) protein product. Neuron 14(5), 1065-1074 (1995).

7. Langbehn DR, Brinkman RR, Falush D, Paulsen JS, Hayden MR: A new model for prediction of the age of onset and penetrance for Huntington's disease based on CAG length. Clin. Genet. 65(4), 267-277 (2004).

8. Duyao MP, Auerbach AB, Ryan A et al.: Inactivation of the mouse Huntington's disease gene homolog HDH. Science 269(5222), 407-410 (1995).
9. Nasir J, Floresco SB, O'Kusky JR et al.: Targeted disruption of the Huntington's disease gene results in embryonic lethality and behavioral and morphological changes in heterozygotes. Cell 81(5), 811-823. (1995).

10. Heng MY, Detloff PJ, Albin RL: Rodent genetic models of Huntington disease. Neurobiol. Dis. 32(1), 1-9 (2008).

11. Ferrante RJ: Mouse models of Huntington's disease and methodological considerations for therapeutic trials. Biochim. Biophys. Acta 1792(6), 506-520 (2009).

12. Levine MS, Cepeda C, Hickey MA, Fleming SM, Chesselet MF: Genetic mouse models of Huntington's and parkinson's diseases: illuminating but imperfect. Trends Neurosci. 27(11), 691-697 (2004). 
13. Ehrnhoefer DE, Butland SL, Pouladi MA, Hayden MR: Mouse models of Huntington disease: variations on a theme. Dis. Model Mech. 2(3-4), 123-129 (2009).

14. Andre VM, Cepeda C, Levine MS: Dopamine and glutamate in Huntington's disease: a balancing act. CNS Neurosci. Ther. 16, 163-178 (2010).

15. Cepeda C, Cummings DM, Andre VM, Holley SM, Levine MS: Genetic mouse models of Huntington's disease: focus on electrophysiological mechanisms. ASN Neuro. 2(2), E00033 (2010).

16. Vonsattel JP, Myers RH, Stevens TJ, Ferrante RJ, Bird ED, Richardson EP Jr: Neuropathological classification of Huntington's disease. J. Neuropathol. Exp. Neurol. 44(6), 559-577. (1985).

17. Bauer PO, Nukina $\mathrm{N}$ : The pathogenic mechanisms of polyglutamine diseases and current therapeutic strategies. J. Neurochem. 110(6), 1737-1765 (2009).

18. Gil JM, Rego AC: Mechanisms of neurodegeneration in Huntington's disease. Eur. J. Neurosci. 27(11), 2803-2820 (2008).

19. Palop JJ, Chin J, Mucke L: A network dysfunction perspective on neurodegenerative diseases. Nature 443(7113), 768-773 (2006).

20. Cepeda C, Wu N, Andre VM, Cummings DM, Levine MS: The corticostriatal pathway in Huntington's disease. Prog. Neurobiol. 81(5-6), 253-271 (2007).

21. Graybiel AM, Aosaki T, Flaherty AW, Kimura M: The basal ganglia and adaptive motor control. Science 265(5180), 1826-1831 (1994).

22. Bolam JP, Hanley JJ, Booth PA, Bevan MD: Synaptic organisation of the basal ganglia. J. Anat. 196 (Pt 4), 527-542 (2000).

23. Kreitzer AC: Physiology and pharmacology of striatal neurons. Annu. Rev. Neurosci. 32, 127-147 (2009).

24. Kreitzer AC, Malenka RC: Striatal plasticity and basal ganglia circuit function. Neuron 60(4), 543-554 (2008).

25. Rymar VV, Sasseville R, Luk KC, Sadikot AF: Neurogenesis and stereological morphometry of calretinin-immunoreactive gabaergic interneurons of the neostriatum. J. Comp. Neurol. 469(3), 325-339 (2004).

26. Kawaguchi Y, Wilson CJ, Augood SJ, Emson PC: Striatal interneurones: chemical, physiological and morphological characterization. Trends Neurosci. 18(12), 527-535. (1995).

27. Gerfen CR: The neostriatal mosaic: multiple levels of compartmental organization. Trends Neurosci. 15(4), 133-139. (1992).
28. Smith Y, Bevan MD, Shink E, Bolam JP: Microcircuitry of the direct and indirect pathways of the basal ganglia. Neuroscience 86(2), 353-387 (1998).

29. Albin RL, Young AB, Penney JB: The functional anatomy of basal ganglia disorders. Trends Neurosci. 12(10), 366-375 (1989).

30. Lei W, Jiao Y, Del Mar N, Reiner A: Evidence for differential cortical input to direct pathway versus indirect pathway striatal projection neurons in rats. J. Neurosci. 24(38), 8289-8299 (2004).

31. Sudhof TC: The synaptic vesicle cycle. Annu. Rev. Neurosci. 27, 509-547 (2004).

32. Gunawardena S, Goldstein LS: Polyglutamine diseases and transport problems: deadly traffic jams on neuronal highways. Arch. Neurol. 62(1), 46-51 (2005).

33. De Vos KJ, Grierson AJ, Ackerley S, Miller CC: Role of axonal transport in neurodegenerative diseases. Annu. Rev. Neurosci. 31, 151-173 (2008).

34. Li H, Li SH, Yu ZX, Shelbourne P, Li XJ: Huntingtin aggregate-associated axonal degeneration is an early pathological event in Huntington's disease mice. J. Neurosci. 21(21), 8473-8481 (2001).

35. Gunawardena S, Her LS, Brusch RG et al.: Disruption of axonal transport by loss of huntingtin or expression of pathogenic polyQ proteins in Drosophila. Neuron 40(1), 25-40 (2003).

36. Szebenyi G, Morfini GA, Babcock A et al.: Neuropathogenic forms of huntingtin and androgen receptor inhibit fast axonal transport. Neuron 40 (1), 41-52 (2003).

37. Chang DT, Rintoul GL, Pandipati S, Reynolds IJ: Mutant huntingtin aggregates impair mitochondrial movement and trafficking in cortical neurons. Neurobiol. Dis. 22(2), 388-400 (2006).

38. Her LS, Goldstein LS: Enhanced sensitivity of striatal neurons to axonal transport defects induced by mutant huntingtin. J. Neurosci. 28(50), 13662-13672 (2008).

39. Trushina E, Dyer RB, Badger JD et al.: Mutant huntingtin impairs axonal trafficking in mammalian neurons in vivo and in vitro. Mol. Cell. Biol. 24(18), 8195-8209 (2004).

40. Sinadinos C, Burbidge-King T, Soh D et al.: Live axonal transport disruption by mutant huntingtin fragments in Drosophila motor neuron axons. Neurobiol. Dis. 34(2), 389-395 (2009).

- Determines that mutant huntingtin (mHtt) expression disrupts fast axonal transport in vivo using time-lapse videomicroscopy and green fluorescent protein-tagged axonal vesicles.
Expression of mHtt caused axonal accumulation and stalling of green fluorescent protein-tagged vesicles.

41. Li H, Wyman T, Yu ZX, Li SH, Li XJ: Abnormal association of mutant huntingtin with synaptic vesicles inhibits glutamate release. Hum. Mol. Genet. 12(16), 2021-2030 (2003).

42. Li XJ, Li SH, Sharp AH et al.: A huntingtinassociated protein enriched in brain with implications for pathology. Nature 378(6555), 398-402. (1995).

43. Martin EJ, Kim M, Velier J et al:: Analysis of huntingtin-associated protein 1 in mouse brain and immortalized striatal neurons. J. Comp. Neurol. 403(4), 421-430 (1999).

44. Engelender S, Sharp AH, Colomer V et al.: Huntingtin-associated protein 1 (HAP1) interacts with the p150Glued subunit of dynactin. Hum. Mol. Genet. 6(13), 2205-2212. (1997).

45. Gauthier LR, Charrin BC, Borrell-Pages M et al.: Huntingtin controls neurotrophic support and survival of neurons by enhancing BDNF vesicular transport along microtubules. Cell 118(1), 127-138 (2004).

46. Smith R, Klein P, Koc-Schmitz Y et al.: Loss of SNAP-25 and rabphilin 3A in sensorymotor cortex in Huntington's disease. J. Neurochem. 103(1), 115-123 (2007).

47. DiProspero NA, Chen EY, Charles V, Plomann M, Kordower JH, Tagle DA: Early changes in Huntington's disease patient brains involve alterations in cytoskeletal and synaptic elements. J. Neurocytol. 33(5), 517-533 (2004).

48. Morton AJ, Faull RL, Edwardson JM: Abnormalities in the synaptic vesicle fusion machinery in Huntington's disease. Brain Res. Bull. 56(2), 111-117 (2001).

49. Smith R, Petersen A, Bates GP, Brundin P, Li JY: Depletion of rabphilin 3a in a transgenic mouse model (R6/1) of Huntington's disease, a possible culprit in synaptic dysfunction. Neurobiol. Dis. 20(3), 673-684 (2005).

50. Modregger J, DiProspero NA, Charles V, Tagle DA, Plomann M: Pacsin 1 interacts with huntingtin and is absent from synaptic varicosities in presymptomatic Huntington's disease brains. Hum. Mol. Genet. 11(21), 2547-2558 (2002).

51. Cepeda C, Hurst RS, Calvert CR et al.: Transient and progressive electrophysiological alterations in the corticostriatal pathway in a mouse model of Huntington's disease. J. Neurosci. 23(3), 961-969 (2003).

52. Joshi PR, Wu NP, Andre VM et al.: Age-dependent alterations of corticostriatal activity in the YAC128 mouse model of Huntington disease. J. Neurosci. 29(8), 2414-2427 (2009). 
53. Gerdeman G, Lovinger DM: $\mathrm{CB}_{1}$ cannabinoid receptor inhibits synaptic release of glutamate in rat dorsolateral striatum. J. Neurophysiol. 85(1), 468-471 (2001).

54. Hsu KS, Huang CC, Yang CH, Gean PW: Presynaptic $\mathrm{D}_{2}$ dopaminergic receptors mediate inhibition of excitatory synaptic transmission in rat neostriatum. Brain Res. 690(2), 264-268 (1995).

55. Lovinger DM, McCool BA: Metabotropic glutamate receptor-mediated presynaptic depression at corticostriatal synapses involves mGlur2 or 3. J. Neurophysiol. 73(3), 1076-1083 (1995).

56. Nisenbaum ES, Berger TW, Grace AA: Presynaptic modulation by $\mathrm{GABA}_{\mathrm{B}}$ receptors of glutamatergic excitation and GABAergic inhibition of neostriatal neurons. J. Neurophysiol. 67(2), 477-481 (1992).

57. Ariano MA, Aronin N, Difiglia M et al.: Striatal neurochemical changes in transgenic models of Huntington's disease. J. Neurosci. Res. 68(6), 716-729. (2002).

58. Cha JH, Kosinski CM, Kerner JA et al.: Altered brain neurotransmitter receptors in transgenic mice expressing a portion of an abnormal human Huntington disease gene. Proc. Natl Acad. Sci. USA 95(11), 6480-6485 (1998).

59. Luthi-Carter R, Strand A, Peters NL et al:: Decreased expression of striatal signaling genes in a mouse model of Huntington's disease. Hum. Mol. Genet. 9(9), 1259-1271 (2000).

60. Dowie MJ, Bradshaw HB, Howard ML et al: : Altered $\mathrm{CB}_{1}$ receptor and endocannabinoid levels precede motor symptom onset in a transgenic mouse model of Huntington's disease. Neuroscience 163(1), 456-465 (2009).

61. Arzberger T, Krampfl K, Leimgruber S, Weindl A: Changes of NMDA receptor subunit (NR1, NR2B) and glutamate transporter (GLT1) mrna expression in Huntington's disease - an in situ hybridization study. J. Neuropathol. Exp. Neurol. 56(4), 440-454 (1997).

62. Hassel B, Tessler S, Faull RL, Emson PC: Glutamate uptake is reduced in prefrontal cortex in Huntington's disease. Neurochem. Res. 33(2), 232-237 (2008).

63. Behrens PF, Franz P, Woodman B, Lindenberg KS, Landwehrmeyer GB: Impaired glutamate transport and glutamate-glutamine cycling: downstream effects of the Huntington mutation. Brain 125(Pt 8), 1908-1922 (2002).

64. Lievens JC, Woodman B, Mahal A et al.: Impaired glutamate uptake in the R6 Huntington's disease transgenic mice. Neurobiol. Dis. 8(5), 807-821 (2001).
65. Shin JY, Fang ZH, Yu ZX, Wang CE, Li SH, Li XJ: Expression of mutant huntingtin in glial cells contributes to neuronal excitotoxicity. J. Cell Biol. 171(6), 1001-1012 (2005).

66. Lievens JC, Rival T, Iche M, Chneiweiss H, Birman S: Expanded polyglutamine peptides disrupt EGF receptor signaling and glutamate transporter expression in Drosophila. Hum. Mol. Genet. 14(5), 713-724 (2005).

67. Miller BR, Dorner JL, Shou M et al.: Up-regulation of GLT1 expression increases glutamate uptake and attenuates the Huntington's disease phenotype in the R6/2 mouse. Neuroscience 153(1), 329-337 (2008).

68. Dorner JL, Miller BR, Barton SJ, Brock TJ, Rebec GV: Sex differences in behavior and striatal ascorbate release in the $140 \mathrm{CAG}$ knock-in mouse model of Huntington's disease. Behav. Brain Res. 178(1), 90-97 (2007).

69. Dorner JL, Miller BR, Klein EL et al.: Corticostriatal dysfunction underlies diminished striatal ascorbate release in the R6/2 mouse model of Huntington's disease. Brain Res. 1290, 111-120 (2009).

70. Rebec GV, Barton SJ, Ennis MD: Dysregulation of ascorbate release in the striatum of behaving mice expressing the Huntington's disease gene. J. Neurosci. 22(2), RC202 (2002).

71. Miele M, Boutelle MG, Fillenz M: The physiologically induced release of ascorbate in rat brain is dependent on impulse traffic, calcium influx and glutamate uptake. Neuroscience 62(1), 87-91 (1994).

72. Li X, Valencia A, Sapp E et al:: Aberrant rab11-dependent trafficking of the neuronal glutamate transporter EAAC1 causes oxidative stress and cell death in Huntington's disease. J. Neurosci. 30(13), 4552-4561 (2010).

73. Robinson MB: The family of sodiumdependent glutamate transporters: a focus on the GLT-1/EAAT2 subtype. Neurochem. Int. 33(6), 479-491 (1998).

74. Danbolt NC: Glutamate uptake. Prog. Neurobiol. 65(1), 1-105 (2001).

75. Tzingounis AV, Wadiche JI: Glutamate transporters: confining runaway excitation by shaping synaptic transmission. Nat. Rev. Neurosci. 8(12), 935-947 (2007).

76. Miller BR, Gaither TW, Dorner JL, Klein EL, Rebec GV: Enhancement of glutamate uptake reverses deficient striatal ascorbate release in the R6/2 model of Huntington's disease. Soc. Neurosci. Abstr. Program No. 432.6 (2009).

77. Estrada Sanchez AM, Mejia-Toiber J, Massieu L: Excitotoxic neuronal death and the pathogenesis of Huntington's disease. Arch. Med. Res. 39(3), 265-276 (2008).
78. Fan MM, Raymond LA: $N$-methyl-Daspartate (NMDA) receptor function and excitotoxicity in Huntington's disease. Prog. Neurobiol. 81(5-6), 272-293 (2007).

79. Dong XX, Wang Y, Qin ZH: Molecular mechanisms of excitotoxicity and their relevance to pathogenesis of neurodegenerative diseases. Acta Pharmacol. Sin. 30 (4), 379-387 (2009).

80. Bezprozvanny I: Calcium signaling and neurodegenerative diseases. Trends Mol. Med. 15(3), 89-100 (2009).

81. Beal MF, Ferrante RJ, Swartz KJ, Kowall NW: Chronic quinolinic acid lesions in rats closely resemble Huntington's disease. J. Neurosci. 11(6), 1649-1659 (1991).

82. Beal MF, Kowall NW, Ellison DW, Mazurek MF, Swartz KJ, Martin JB: Replication of the neurochemical characteristics of Huntington's disease by quinolinic acid. Nature 321(6066), 168-171 (1986).

83. Milnerwood AJ, Raymond LA: Synaptic abnormalities associated with Huntington's disease. In: Molecular Mechanisms of Synaotogenesis. Dityatev A-H (Ed.). Springer, NY, USA, 457-469 (2006).

84. Kuppenbender KD, Standaert DG, Feuerstein TJ, Penney JB Jr, Young AB, Landwehrmeyer GB: Expression of NMDA receptor subunit mRNAs in neurochemically identified projection and interneurons in the human striatum. J. Comp. Neurol. 419(4), 407-421 (2000).

85. Landwehrmeyer GB, Standaert DG, Testa CM, Penney JB Jr, Young AB: NMDA receptor subunit mRNA expression by projection neurons and interneurons in rat striatum. J. Neurosci. 15 (7 Pt 2), 5297-5307 (1995).

86. Bezprozvanny I, Hayden MR: Deranged neuronal calcium signaling and Huntington disease. Biochem. Biophys. Res. Commun. 322(4), 1310-1317 (2004).

87. Li L, Fan M, Icton CD et al:: Role of NR2B-type nmda receptors in selective neurodegeneration in Huntington disease. Neurobiol. Aging 24(8), 1113-1121 (2003).

88. Chen N, Luo T, Wellington C et al:: Subtype-specific enhancement of NMDA receptor currents by mutant huntingtin. J. Neurochem. 72(5), 1890-1898. (1999).

89. Zeron MM, Chen N, Moshaver A et al:: Mutant huntingtin enhances excitotoxic cell death. Mol. Cell. Neurosci. 17(1), 41-53. (2001).

90. Zeron MM, Hansson O, Chen $\mathrm{N}$ et al.: Increased sensitivity to $N$-methyl-D-aspartate receptor-mediated excitotoxicity in a mouse model of Huntington's disease. Neuron 33(6), 849-860 (2002). 
91. Zhang H, Li Q, Graham RK, Slow E, Hayden MR, Bezprozvanny I: Full length mutant huntingtin is required for altered $\mathrm{Ca}^{2+}$ signaling and apoptosis of striatal neurons in the YAC mouse model of Huntington's disease. Neurobiol. Dis. 31(1), 80-88 (2008).

92. Tang TS, Slow E, Lupu V et al.: Disturbed $\mathrm{Ca}^{2+}$ signaling and apoptosis of medium spiny neurons in Huntington's disease. Proc. Natl Acad. Sci. USA 102(7), 2602-2607 (2005).

93. Ali NJ, Levine MS: Changes in expression of $N$-methyl-D-aspartate receptor subunits occur early in the R6/2 mouse model of Huntington's disease. Dev. Neurosci. 28(3), 230-238 (2006).

94. Li JH, Wang YH, Wolfe BB et al.:

Developmental changes in localization of NMDA receptor subunits in primary cultures of cortical neurons. Eur. J. Neurosci. 10(5), 1704-1715 (1998).

95. Stocca G, Vicini S: Increased contribution of NR2A subunit to synaptic NMDA receptors in developing rat cortical neurons. J. Physiol. 507(Pt 1), 13-24 (1998).

96. Tovar KR, Westbrook GL: The incorporation of NMDA receptors with a distinct subunit composition at nascent hippocampal synapses in vitro. J. Neurosci. 19(10), 4180-4188 (1999).

97. Papadia S, Hardingham GE: The dichotomy of NMDA receptor signaling. Neuroscientist 13(6), 572-579 (2007).

98. Vanhoutte P, Bading H: Opposing roles of synaptic and extrasynaptic NMDA receptors in neuronal calcium signalling and $B D N F$ gene regulation. Curr. Opin. Neurobiol. 13(3), 366-371 (2003).

99. Gouix E, Leveille F, Nicole O, Melon C, Had-Aissouni L, Buisson A: Reverse glial glutamate uptake triggers neuronal cell death through extrasynaptic NMDA receptor activation. Mol. Cell. Neurosci. 40(4), 463-473 (2009).

100. Hardingham GE, Fukunaga Y, Bading H: Extrasynaptic nmdars oppose synaptic nmdars by triggering CREB shut-off and cell death pathways. Nat. Neurosci. 5(5), 405-414 (2002).

101. Papadia S, Soriano FX, Leveille F et al:: Synaptic NMDA receptor activity boosts intrinsic antioxidant defenses. Nat. Neurosci. 11(4), 476-487 (2008).

102. Milnerwood AJ, Gladding CM, Pouladi MA et al.: Early increase in extrasynaptic NMDA receptor signaling and expression contributes to phenotype onset in Huntington's disease mice. Neuron 65 (2), 178-190 (2010).

- Determines that extrasynaptic $N$-methylD-aspartate receptor (NMDAR) expression and currents are specifically increased, while CREB activation is reduced in Huntinton's disease (HD). Blockade of extransynaptic NMDARs with memantine reversed altered currents and attenuated HD motor learning deficits.

103. Li L, Murphy TH, Hayden MR, Raymond LA: Enhanced striatal NR2Bcontaining $N$-methyl-D-aspartate receptormediated synaptic currents in a mouse model of Huntington disease. J. Neurophysiol. 92(5), 2738-2746 (2004).

104. Heng MY, Detloff PJ, Wang PL, Tsien JZ, Albin RL: In vivo evidence for NMDA receptor-mediated excitotoxicity in a murine genetic model of Huntington disease. J. Neurosci. 29(10), 3200-3205 (2009).

105. Slow EJ, Graham RK, Osmand AP et al.: Absence of behavioral abnormalities and neurodegeneration in vivo despite widespread neuronal huntingtin inclusions. Proc. Natl Acad. Sci. USA 102(32), 11402-11407 (2005).

106. Okamoto S, Pouladi MA, Talantova M et al.: Balance between synaptic versus extrasynaptic nmda receptor activity influences inclusions and neurotoxicity of mutant huntingtin. Nat. Med. 15(12), 1407-1413 (2009).

-. Determines that activation of extrasynaptic NMDARs (NR2B) promotes neurotoxicity, while activation of presynaptic NMDARs (NR2A) reduces neurotoxicity and ameliorates $\mathrm{HD}$ motor signs.

107. Sun Y, Savanenin A, Reddy PH, Liu YF: Polyglutamine-expanded huntingtin promotes sensitization of $N$-methyl-D-aspartate receptors via post-synaptic density 95. J. Biol. Chem. 276(27), 24713-24718 (2001).

108. Song C, Zhang Y, Parsons CG, Liu YF: Expression of polyglutamine-expanded huntingtin induces tyrosine phosphorylation of $N$-methyl-D-aspartate receptors. J. Biol. Chem. 278(35), 33364-33369 (2003).

109. Fan J, Cowan CM, Zhang LY, Hayden MR, Raymond LA: Interaction of postsynaptic density protein- 95 with $n$ mda receptors influences excitotoxicity in the yeast artificial chromosome mouse model of Huntington's disease. J. Neurosci. 29(35), 10928-10938 (2009).

110. Fan MM, Fernandes HB, Zhang LY, Hayden MR, Raymond LA: Altered NMDA receptor trafficking in a yeast artificial chromosome transgenic mouse model of Huntington's disease. J. Neurosci. 27(14), 3768-3779 (2007).

111. Wu J, Tang T, Bezprozvanny I: Evaluation of clinically relevant glutamate pathway inhibitors in in vitro model of Huntington's disease. Neurosci. Lett. 407(3), 219-223 (2006).
112. Ondo WG, Mejia NI, Hunter CB: A pilot study of the clinical efficacy and safety of memantine for Huntington's disease. Parkinsonism Relat. Disord. 13(7), 453-454 (2007).

113. Nakanishi S: Molecular diversity of glutamate receptors and implications for brain function. Science 258(5082), 597-603 (1992).

114. Schoepp DD, Conn PJ: Metabotropic glutamate receptors in brain function and pathology. Trends Pharmacol. Sci. 14(1), 13-20 (1993).

115. Pisani A, Bernardi G, Bonsi P, Centonze D, Giacomini P, Calabresi P: Cell-type specificity of mGlur activation in striatal neuronal subtypes. Amino Acids 19(1), 119-129 (2000).

116. Benn CL, Slow EJ, Farrell LA et al:: Glutamate receptor abnormalities in the YAC128 transgenic mouse model of Huntington's disease. Neuroscience 147(2), 354-372 (2007).

117. Bruno V, Battaglia G, Copani A et al.: An activity-dependent switch from facilitation to inhibition in the control of excitotoxicity by group I metabotropic glutamate receptors. Eur. J. Neurosci. 13(8), 1469-1478 (2001).

118. Kerner JA, Standaert DG, Penney JB Jr, Young AB, Landwehrmeyer GB: Expression of group one metabotropic glutamate receptor subunit mrnas in neurochemically identified neurons in the rat neostriatum, neocortex, and hippocampus. Brain Res. Mol. Brain Res. 48(2), 259-269 (1997).

119. Mao L, Wang JQ: Upregulation of preprodynorphin and preproenkephalin mRNA expression by selective activation of group I metabotropic glutamate receptors in characterized primary cultures of rat striatal neurons. Brain Res. Mol. Brain Res. 86(1-2), 125-137 (2001).

120. Tallaksen-Greene SJ, Kaatz KW, Romano C, Albin RL: Localization of mGlurla-like immunoreactivity and mGlur5-like immunoreactivity in identified populations of striatal neurons. Brain Res. 780(2), 210-217 (1998).

121. Testa CM, Standaert DG, Landwehrmeyer GB, Penney JB Jr, Young AB: Differential expression of mGlur5 metabotropic glutamate receptor mRNA by rat striatal neurons. J. Comp. Neurol. 354(2), 241-252. (1995).

122. Tang TS, Tu H, Chan EY et al.: Huntingtin and huntingtin-associated protein 1 influence neuronal calcium signaling mediated by inositol- $(1,4,5)$ triphosphate receptor type 1. Neuron 39(2), 227-239 (2003).

123. Ribeiro FM, Paquet M, Ferreira LT et al.: Metabotropic glutamate receptor-mediated cell signaling pathways are altered in a mouse model of Huntington's disease. J. Neurosci. 30(1), 316-324 (2010). 
124. Hou L, Klann E: Activation of the phosphoinositide 3-kinase-AKT-mammalian target of rapamycin signaling pathway is required for metabotropic glutamate receptor-dependent long-term depression. J. Neurosci. 24(28), 6352-6361 (2004).

125. Mao L, Yang L, Tang Q, Samdani S, Zhang G, Wang JQ: The scaffold protein Homerlb/c links metabotropic glutamate receptor 5 to extracellular signal-regulated protein kinase cascades in neurons. J. Neurosci. 25(10), 2741-2752 (2005).

126. Rong R, Ahn JY, Huang H et al.: PI3 kinase enhancer-homer complex couples mGlurI to PI3 kinase, preventing neuronal apoptosis. Nat. Neurosci. 6(11), 1153-1161 (2003).

127. Cheah BC, Vucic S, Krishnan AV, Kiernan MC: Riluzole, neuroprotection and amyotrophic lateral sclerosis. Curr. Med. Chem. 17(18), 1942-1199 (2010).

128. Doble A: The pharmacology and mechanism of action of riluzole. Neurology 47(6 Suppl. 4), S233-S241 (1996).

129. Miller RG, Mitchell JD, Lyon M, Moore DH: Riluzole for amyotrophic lateral sclerosis (ALS)/motor neuron disease (MND). Cochrane Database Syst. Rev. (1), CD001447 (2007).

130. Schiefer J, Landwehrmeyer GB, Luesse HG et al.: Riluzole prolongs survival time and alters nuclear inclusion formation in a transgenic mouse model of Huntington's disease. Mov. Disord. 17(4), 748-757 (2002).

131. Landwehrmeyer GB, Dubois B, de Yebenes JG et al:: Riluzole in Huntington's disease: a 3-year, randomized controlled study. Ann. Neurol. 62(3), 262-272 (2007).

132. Huntington Study Group: Dosage effects of riluzole in Huntington's disease: a multicenter placebo-controlled study. Neurology 61(11), 1551-1556 (2003).

133. Schiefer J, Sprunken A, Puls C et al.: The metabotropic glutamate receptor 5 antagonist MPEP and the mGlur2 agonist LY379268 modify disease progression in a transgenic mouse model of Huntington's disease. Brain Res. 1019(1-2), 246-254 (2004).

134. Milnerwood AJ, Raymond LA: Corticostriatal synaptic function in mouse models of Huntington's disease: early effects of huntingtin repeat length and protein load. J. Physiol. 585(Pt 3), 817-831 (2007).

135. Andre VM, Cepeda C, Venegas A, Gomez Y, Levine MS: Altered cortical glutamate receptor function in the R6/2 model of Huntington's disease. J. Neurophysiol. 95(4), 2108-2119 (2006).
136. Cummings DM, Andre VM, Uzgil BO et al.: Alterations in cortical excitation and inhibition in genetic mouse models of Huntington's disease. J. Neurosci. 29(33), 10371-10386 (2009).

- Demonstrates overt alterations in cortical excitation and inhibition in the R6/2, yeast artificial chromosome (YAC) 128, and 140CAG knock-in mouse models of HD. Overall, excitation was enhanced and inhibition was initially increased but was later reduced, revealing alterations that are opposite to what is observed in medium spiny neurons (MSNs).

137. Piccini P: Neurodegenerative movement disorders: the contribution of functional imaging. Curr. Opin. Neurol. 17(4), 459-466 (2004).

138. Kennedy L, Shelbourne PF, Dewar D: Alterations in dopamine and benzodiazepine receptor binding precede overt neuronal pathology in mice modelling early Huntington disease pathogenesis. Brain Res. 1039(1-2), 14-21 (2005).

139. Bibb JA, Yan Z, Svenningsson P et al.: Severe deficiencies in dopamine signaling in presymptomatic Huntington's disease mice. Proc. Natl Acad. Sci. USA 97(12), 6809-6814 (2000).

140. Jarabek BR, Yasuda RP, Wolfe BB: Regulation of proteins affecting NMDA receptor-induced excitotoxicity in a Huntington's mouse model. Brain 127(Pt 3), 505-516 (2004).

141. Petersen A, Puschban Z, Lotharius J et al.: Evidence for dysfunction of the nigrostriatal pathway in the R6/1 line of transgenic Huntington's disease mice. Neurobiol. Dis. 11(1), 134-146 (2002).

142. Johnson MA, Rajan V, Miller CE, Wightman RM: Dopamine release is severely compromised in the R6/2 mouse model of Huntington's disease. J. Neurochem. 97(3), 737-746 (2006).

143. Johnson MA, Villanueva M, Haynes CL, Seipel AT, Buhler LA, Wightman RM: Catecholamine exocytosis is diminished in R6/2 Huntington's disease model mice. J. Neurochem. 103(5), 2102-2110 (2007).

144. Ortiz AN, Kurth BJ, Osterhaus GL, Johnson MA: Dysregulation of intracellular dopamine stores revealed in the R6/2 mouse striatum. J. Neurochem. 112(3), 755-761 (2010).

145. Kuczenski R, Segal DS: Differential effects of amphetamine and dopamine uptake blockers (cocaine, nomifensine) on caudate and accumbens dialysate dopamine and 3-methoxytyramine. J. Pharmacol. Exp. Ther. 262(3), 1085-1094 (1992).
146. Hickey MA, Reynolds GP, Morton AJ: The role of dopamine in motor symptoms in the R6/2 transgenic mouse model of Huntington's disease. J. Neurochem. 81(1), 46-59 (2002).

147. Surmeier DJ, Ding J, Day M, Wang Z, Shen W: $\mathrm{D}_{1}$ and $\mathrm{D}_{2}$ dopamine-receptor modulation of striatal glutamatergic signaling in striatal medium spiny neurons. Trends Neurosci. 30(5), 228-235 (2007).

148. Klawans HC, Paulson GW, Barbeau A: Predictive test for Huntington's chorea. Lancet 2 (7684), 1185-1186 (1970).

149. Cass WA: Decreases in evoked overflow of dopamine in rat striatum after neurotoxic doses of methamphetamine. J. Pharmacol. Exp. Ther. 280(1), 105-113 (1997).

150. Roos RA, Pruyt JF, de Vries J, Bots GT: Neuronal distribution in the putamen in Huntington's disease. J. Neurol. Neurosurg. Psychiatry 48(5), 422-425 (1985).

151. Zhuang X, Oosting RS, Jones SR et al.: Hyperactivity and impaired response habituation in hyperdopaminergic mice. Proc. Natl Acad. Sci. USA 98(4), 1982-1987 (2001).

152. Cyr M, Beaulieu JM, Laakso A et al: Sustained elevation of extracellular dopamine causes motor dysfunction and selective degeneration of striatal GABAergic neurons. Proc. Natl Acad. Sci. USA 100 (19), 11035-11040 (2003).

153. Charvin D, Vanhoutte P, Pages C, Borrelli E, Caboche J: Unraveling a role for dopamine in Huntington's disease: the dual role of reactive oxygen species and $\mathrm{D}_{2}$ receptor stimulation. Proc. Natl Acad. Sci. USA 102(34), 12218-12223 (2005).

154. Jakel RJ, Maragos WF: Neuronal cell death in Huntington's disease: a potential role for dopamine. Trends Neurosci. 23(6), 239-245 (2000).

155. Wersinger C, Chen J, Sidhu A: Bimodal induction of dopamine-mediated striatal neurotoxicity is mediated through both activation of $\mathrm{D}_{1}$ dopamine receptors and autoxidation. Mol. Cell. Neurosci. 25(1), 124-137 (2004).

156. Benchoua A, Trioulier Y, Diguet E et al.: Dopamine determines the vulnerability of striatal neurons to the $N$-terminal fragment of mutant huntingtin through the regulation of mitochondrial complex II. Hum. Mol. Genet. 17(10), 1446-1456 (2008).

157. Tang TS, Chen X, Liu J, Bezprozvanny I: Dopaminergic signaling and striatal neurodegeneration in Huntington's disease. J. Neurosci. 27(30), 7899-7910 (2007). 
- Discovers that glutamate and dopamine signaling pathways act synergistically to induce elevated intracellular $\mathrm{Ca}^{2}$ signals and apoptosis of $\mathrm{mHtt}$-expressing MSNs. Treatment with tetrabenazine alleviated motor deficits and reduced striatal cell loss, while persistent elevation of striatal dopamine exacerbated motor deficits in YAC128 mice.

158. Paoletti P, Vila I, Rife M, Lizcano JM, Alberch J, Gines S: Dopaminergic and glutamatergic signaling crosstalk in Huntington's disease neurodegeneration: the role of p25/cyclin-dependent kinase 5 . J. Neurosci. 28(40), 10090-10101 (2008).

159. Cyr M, Sotnikova TD, Gainetdinov RR, Caron MG: Dopamine enhances motor and neuropathological consequences of polyglutamine expanded huntingtin. FASEB J. 20(14), 2541-2543 (2006).

160. Scherman D, Jaudon P, Henry JP: Characterization of the monoamine carrier of chromaffin granule membrane by binding of [2-3H] dihydrotetrabenazine. Proc. Natl Acad. Sci. USA 80(2), 584-588 (1983).

161. Wang H, Chen X, Li Y, Tang TS, Bezprozvanny I: Tetrabenazine is neuroprotective in Huntington's disease mice. Mol. Neurodegener. 5, 18 (2010).

162. Bozzi Y, Borrelli E: Dopamine in neurotoxicity and neuroprotection: what do $\mathrm{D}_{2}$ receptors have to do with it? Trends Neurosci. 29(3), 167-174 (2006).

163. Bamford NS, Robinson S, Palmiter RD, Joyce JA, Moore C, Meshul CK: Dopamine modulates release from corticostriatal terminals. J. Neurosci. 24(43), 9541-9552 (2004).

164. Savani AA, Login IS: Tetrabenazine as antichorea therapy in Huntington disease: a randomized controlled trial. Neurology 68(10), 797; author reply 797 (2007).

165. Huntington Study Group: Tetrabenazine as antichorea therapy in Huntington disease: a randomized controlled trial. Neurology 66(3), 366-372 (2006)

166. Kenney C, Hunter C, Mejia N, Jankovic J: Is history of depression a contraindication to treatment with tetrabenazine? Clin. Neuropharmacol. 29(5), 259-264 (2006).

167. Carlsson ML, Carlsson A, Nilsson M: Schizophrenia: from dopamine to glutamate and back. Curr. Med. Chem. 11(3), 267-277 (2004).

168. Rung JP, Rung E, Helgeson L et al: Effects of --OSU6162 and ACR16 on motor activity in rats, indicating a unique mechanism of dopaminergic stabilization. J. Neural. Transm. 115(6), 899-908 (2008).
169. Berridge MJ: Neuronal calcium signaling. Neuron 21(1), 13-26. (1998).

170. Kaltenbach LS, Romero E, Becklin RR et al.: Huntingtin interacting proteins are genetic modifiers of neurodegeneration. PLoS Genet. 3(5), E82 (2007).

171. Tang TS, Guo C, Wang H, Chen X, Bezprozvanny I: Neuroprotective effects of inositol 1,4,5-trisphosphate receptor $C$-terminal fragment in a Huntington's disease mouse model. J. Neurosci. 29(5), 1257-1266 (2009).

- Demonstrates that viral inhibition of $\mathrm{mHtt}$ inassociation with $\mathrm{Ins} \mathrm{P}_{3}$ receptor 1-stabilized $\mathrm{Ca}^{2+}$ signaling was neuroprotective in vitro and in vivo and alleviated the motor deficit in YAC128 mice.

172. Bargas J, Howe A, Eberwine J, Cao Y, Surmeier DJ: Cellular and molecular characterization of $\mathrm{Ca}^{2+}$ currents in acutely isolated, adult rat neostriatal neurons. J. Neurosci. 14(11 Pt 1), 6667-6686 (1994).

173. Swayne LA, Chen L, Hameed S et al.: Crosstalk between huntingtin and syntaxin $1 \mathrm{~A}$ regulates $\mathrm{N}$-type calcium channels. Mol. Cell. Neurosci. 30(3), 339-351 (2005).

174. Cepeda C, Ariano MA, Calvert CR et al.: NMDA receptor function in mouse models of Huntington disease. J. Neurosci. Res. 66(4), 525-539 (2001).

175. Starling AJ, Andre VM, Cepeda C, de Lima M, Chandler SH, Levine MS: Alterations in $\mathrm{N}$-methyl-D-aspartate receptor sensitivity and magnesium blockade occur early in development in the R6/2 mouse model of Huntington's disease. J. Neurosci. Res 82(3), 377-386 (2005).

176. Romero E, Cha GH, Verstreken P et al.: Suppression of neurodegeneration and increased neurotransmission caused by expanded full-length huntingtin accumulating in the cytoplasm. Neuron 57(1), 27-40 (2008).

177. Chan CS, Guzman JN, Ilijic E et al.: 'Rejuvenation' protects neurons in mouse models of Parkinson's disease. Nature 447(7148), 1081-1086 (2007).

178. Bachurin S, Bukatina E, Lermontova N et al:: Antihistamine agent dimebon as a novel neuroprotector and a cognition enhancer. Ann. NY Acad. Sci. 939, 425-435 (2001).

179. Doody RS, Gavrilova SI, Sano M et al.: Effect of dimebon on cognition, activities of daily living, behaviour, and global function in patients with mild-to-moderate Alzheimer's disease: a randomised, double-blind, placebo-controlled study. Lancet 372(9634), 207-215 (2008).
180. Kieburtz K, McDermott MP, Voss TS et al.: A randomized, placebo-controlled trial of latrepirdine in Huntington disease. Arch. Neurol. 67(2), 154-160 (2010).

181. Bezprozvanny I: The rise and fall of dimebon. Drug News \& Perspectives (2010) (In press).

182. Grigorev VV, Dranyi OA, Bachurin SO: Comparative study of action mechanisms of dimebon and memantine on AMPA- and NMDA-subtypes glutamate receptors in rat cerebral neurons. Bull. Exp. Biol. Med. 136(5), 474-477 (2003).

183. Lermontova NN, Redkozubov AE, Shevtsova EF, Serkova TP, Kireeva EG, Bachurin SO: Dimebon and tacrine inhibit neurotoxic action of $\beta$-amyloid in culture and block l-type $\mathrm{Ca}^{2+}$ channels. Bull. Exp. Biol. Med. 132(5), 1079-1083 (2001).

184. Bachurin SO, Shevtsova EP, Kireeva EG, Oxenkrug GF, Sablin SO: Mitochondria as a target for neurotoxins and neuroprotective agents. Ann. NY Acad. Sci. 993, 334-344; discussion 345-339 (2003).

185. Wu J, Li Q, Bezprozvanny I: Evaluation of Dimebon in cellular model of Huntington's disease. Mol. Neurodegener. 3(1), 15 (2008).

186. Okun I, Tkachenko ES, Khvat A, Mitkin O, Kazey V, Ivachtchenko VA: From anti-allergic to anti-Alzheimer's: molecular pharmacology of Dimebon. Curr. Alzheimer Res. 7(2), 97-112 (2010).

187. Upton N, Chuang TT, Hunter AJ, Virley DJ: 5-HT6 receptor antagonists as novel cognitive enhancing agents for Alzheimer's disease. Neurotherapeutics 5(3), 458-469 (2008).

188. Schaffhauser H, Mathiasen JR, Dicamillo A et al.: Dimebolin is a 5-HT6 antagonist with acute cognition enhancing activities. Biochem. Pharmacol. 78(8), 1035-1042 (2009).

189. Steele JW, Kim SH, Cirrito JR et al.: Acute dosing of latrepirdine (Dimebon), a possible alzheimer therapeutic, elevates extracellular amyloid- $\beta$ levels in vitro and in vivo. Mol. Neurodegener. 4, 51 (2009).

190. Yamashita M, Nonaka T, Arai T et al.: Methylene blue and Dimebon inhibit aggregation of TDP-43 in cellular models. FEBS Lett. 583(14), 2419-2424 (2009).

191. Arai T, Hasegawa M, Nonoka T et al.: Phosphorylated and cleaved TDP-43 in ALS, FTLD and other neurodegenerative disorders and in cellular models of TDP-43 proteinopathy. Neuropathology 30(2), 170-181 (2010).

192. Klapstein GJ, Fisher RS, Zanjani H et al.: Electrophysiological and morphological changes in striatal spiny neurons in R6/2 Huntington's disease transgenic mice. J. Neurophysiol. 86(6), 2667-2677 (2001). 
193. Rebec GV, Conroy SK, Barton SJ:

Hyperactive striatal neurons in symptomatic Huntington R6/2 mice: variations with behavioral state and repeated ascorbate treatment. Neuroscience 137(1), 327-336 (2006).

194. Miller BR, Walker AG, Shah AS, Barton SJ, Rebec GV: Dysregulated information processing by medium spiny neurons in striatum of freely behaving mouse models of Huntington's disease. J. Neurophysiol. 100(4), 2205-2216 (2008).

- Demonstrates marked dysregulation of activity patterns in MSNs from behaving R6/2 and 140CAG knock-in mice. Showed that neuronal population activity was uncoordinated in both models relative to wild-types.

195. von Horsten S, Schmitt I, Nguyen HP et al: Transgenic rat model of Huntington's disease. Hum. Mol. Genet. 12(6), 617-624 (2003).

196. Miller BR, Walker AG, Fowler SC et al: Dysregulation of coordinated neuronal firing patterns in striatum of freely behaving transgenic rats that model Huntington's disease. Neurobiol. Dis. 37(1), 106-113 (2010).

197. Walker AG, Miller BR, Fritsch JN, Barton SJ, Rebec GV: Altered information processing in the prefrontal cortex of Huntington's disease mouse models. J. Neurosci. 28(36), 8973-8982 (2008).

198. Walker LJ, Miller BR, Barton SJ, Rebec GV: Altered neuronal firing patterns in motor cortex (M1) of the R6/2 model of Huntington's disease. Soc. Neurosci. Abstr. Program No. 432.12 (2009).
199. Wilson CJ, Kawaguchi Y: The origins of two-state spontaneous membrane potential fluctuations of neostriatal spiny neurons. J. Neurosci. 16(7), 2397-2410 (1996).

200. Rebec GV, Barton SJ, Marseilles AM, Collins K: Ascorbate treatment attenuates the Huntington behavioral phenotype in mice. Neuroreport 14(9), 1263-1265 (2003).

201. Beister A, Kraus P, Kuhn W, Dose M, Weindl A, Gerlach M: The $N$-methyl-Daspartate antagonist memantine retards progression of Huntington's disease. J. Neural. Transm. Suppl. (68), 117-122 (2004).

202. Deng YP, Albin RL, Penney JB, Young AB, Anderson KD, Reiner A: Differential loss of striatal projection systems in Huntington's disease: a quantitative immunohistochemical study. J. Chem. Neuroanat. 27(3), 143-164 (2004).

203. Richfield EK, Maguire-Zeiss KA, Vonkeman HE, Voorn P: Preferential loss of preproenkephalin versus preprotachykinin neurons from the striatum of Huntington's disease patients. Ann. Neurol. 38(6), 852-861 (1995).

204. Cepeda C, Andre VM, Yamazaki I, Wu N, Kleiman-Weiner M, Levine MS: Differential electrophysiological properties of dopamine $\mathrm{D}_{1}$ and $\mathrm{D}_{2}$ receptor-containing striatal medium-sized spiny neurons. Eur. J. Neurosci. 27(3), 671-682 (2008).

- Demonstrates that $\mathrm{D}_{2}$-containing MSNs (indirect pathway) are more excitable (e.g., increased frequency of spontaneous excitatory postsynaptic currents and large amplitude inward currents) than $D_{1}$-containing MSNs of the direct pathway.
205. Picconi B, Passino E, Sgobio C et al.: Plastic and behavioral abnormalities in experimental Huntington's disease: a crucial role for cholinergic interneurons. Neurobiol. Dis. 22(1), 143-152 (2006).

206. Ilieva H, Polymenidou M, Cleveland DW: Non-cell autonomous toxicity in neurodegenerative disorders: ALS and beyond. J. Cell Biol. 187(6), 761-772 (2009).

207. Lobsiger CS, Cleveland DW: Glial cells as intrinsic components of non-cell-autonomous neurodegenerative disease. Nat. Neurosci. 10(11), 1355-1360 (2007).

208. Gu X, Li C, Wei W et al.: Pathological cell-cell interactions elicited by a neuropathogenic form of mutant huntingtin contribute to cortical pathogenesis in HD mice. Neuron 46(3), 433-444 (2005).

- Demonstrates that progressive motor deficits and cortical neuropathology are only observed when mHtt is expressed in all neuron types, but not when restricted to cortical pyramidal neurons. This study was the first to establish that $\mathrm{mHtt}$ expression in multiple cell types (i.e., cell-cell interactions) contributes to HD neuropathology.

209. Brown TB, Bogush AI, Ehrlich ME: Neocortical expression of mutant huntingtin is not required for alterations in striatal gene expression or motor dysfunction in a transgenic mouse. Hum. Mol. Genet. 17(20), 3095-3104 (2008). 